\title{
Assessment of anxiety in older adults: a review of self-report measures
}

This article was published in the following Dove Press journal:

Clinical Interventions in Aging

\section{Michela Balsamo \\ Fedele Cataldi \\ Leonardo Carlucci \\ Beth Fairfield}

Department of Psychological, Health, and Territorial Sciences, Gabriele d'Annunzio University of ChietiPescara, Chieti, Italy
Correspondence: Michela Balsamo Department of Psychological, Health, and Territorial Sciences, Gabriele d'Annunzio University of Chieti-Pescara, 3I via dei Vestini, Chieti, Abruzzo 66100, Italy Tel +39 087I 3555309 Email michela.balsamo@libero.it

\begin{abstract}
With increasing numbers of older adults in the general population, anxiety will become a widespread problem in late life and one of the major causes of health care access contributing to high societal and individual costs. Unfortunately, the detection of anxiety disorders in late life is complicated by a series of factors that make it different from assessment in younger cohorts, such as differential symptom presentation, high comorbidity with medical and mental disorders, the aging process, and newly emergent changes in life circumstances. This review covers commonly and currently used self-report inventories for assessing anxiety in older adults. For each tool, psychometric data is investigated in depth. In particular, information about reliability, validity evidence based on data from clinical and nonclinical samples of older adults, and availability of age-appropriate norms are provided. Finally, guidance for clinical evaluation and future research are proposed in an effort to highlight the importance of clinical assessment in the promotion of clinically relevant therapeutic choices.
\end{abstract}

Keywords: anxiety, elderly, self-report, assessment, aging, psychometric properties

\section{Introduction}

Late-life anxiety is a highly prevalent psychiatric condition. ${ }^{1-4} \mathrm{With}$ growing number of elderly worldwide, anxiety will become a widespread problem in late life, elevating numbers accessing health care and individual and social costs. ${ }^{5}$ Prevalence rates of anxiety disorders among older adults are $1.2 \%-15 \%$ in community samples and $1 \%-28 \%$ in clinical samples of older adults. ${ }^{5-7}$ Evaluating the clinical expression and intensity of anxiety in older adults represents a significant change in research and clinical areas.

\section{Late-life anxiety assessment}

Despite its increasing personal and societal impact, assessment of late-life anxiety has received relatively little attention in psychiatric research. ${ }^{8}$ Unluckily, detecting anxiety disorders in older people is made difficult through several factors, which make it different from assessment in younger cohorts. ${ }^{5,9-13}$ Some of the main factors contributing to produce difficulties in the assessment of late-life anxiety compared with younger cohorts are described in the following sections.

\section{Differential symptom presentation}

Aging-related differences in anxiety symptoms are well known. ${ }^{5}$ Research on affect phenomenology has shown that older adults may experience affect or interpret affective terms differently. ${ }^{14}$ For example, older adults report more concern about health compared to younger adults, whose worries are more focused on finances and 
family; ${ }^{15}$ report less of virtually every negative affective factor (eg, depression, anxiety, guilt, shyness, and hostility) than younger adults; ${ }^{14}$ are more likely to experience anxiety directly (eg, fearful, scared, afraid) compared to younger adults, whose anxiety was more characterized by shame or guilt (eg, ashamed of something, guilty, like you did something wrong) $;{ }^{14}$ and report particular fear situations or objects generally not included on existing fear surveys, such as fear of being a burden on their families. ${ }^{16}$

Importantly, age-related factors also arise in self-reported communication of the experiences of anxiety. For example, in discussing negative emotions, older adults are often more reluctant to report than younger adults and thus more likely to minimize their own psychological symptoms. ${ }^{17-19}$ Additionally, they are less likely to endorse statements that use absolute terms on mental health measures. ${ }^{20-22}$ This tendency could explain the diminished reliability associated with items of anxiety measures using words like "never" or "always". ${ }^{20}$ This evidence suggests the presence of multiple and important implications for anxiety assessment. It is unclear if many of the current tools take into account the uniqueness of the experience and phenomenology of anxiety in older adults. ${ }^{10}$

\section{High medical comorbidities}

Since there has been an increase in the incidence of physical illness with the growing age of individuals, ${ }^{23}$ a higher rate of medical comorbidity and correlated pharmacotherapies often complicate the diagnosis and evaluation of anxiety in elderly. ${ }^{5,10,11,24,25}$ Due to their original use with younger adults, existing anxiety diagnostic criteria and measures for older adults were heavily weighted with somatic items, making the differentiation between medical and psychological causes of anxiety complicated in this population. Nevertheless, somatic experiences are core aspects of many anxiety disorders and to ignore them would be equivalent to exclude crucial symptoms of anxiety. ${ }^{26}$ The difficulty in differentiating anxiety from medical disorders and the overall ubiquity of sleep difficulties in late life might have led to the limited reliability of the somatic items of anxiety measures used with older respondents. ${ }^{27}$ Measures for the assessment of anxiety in elderly might be improved by attributing the right weight to the typical features of anxiety in this population, such as age-relevant aspects of psychological and physical health status. ${ }^{13}$

\section{High comorbidity with other mental disorders}

There is evidence that anxiety and depression share a common component of general distress and components specific to each among younger and older adults. ${ }^{10,28}$ With age, anxiety and depression comorbidity seems to increase, with about half of depressed older adults meeting criteria for a coexisting anxiety disorder. ${ }^{29-32}$ Indeed, several authors have emphasized the fact that anxiety may be part of the phenomenology of late-life depression. ${ }^{33}$ The coexistence of anxiety and dementia is quite common, too. ${ }^{34}$ Several aspects make the assessment process of anxiety states more complicated in older people with dementia. The development of anxiety in these patients is often associated with memory impairment or confusion, ${ }^{34}$ may be a mark of agitation, a typical feature in the behavioral manifestation of dementia, ${ }^{35}$ and is not always detected, because of their inability to report their own subjective experiences accurately. ${ }^{10,36}$ Therefore, the potential interrelations among anxiety and medical factors suggest the inclusion of additional psychopathologic conditions and comprehensive physical examination to exclude medical variables in the assessment of clinical anxiety.

\section{Aging process}

Several factors that are associated with the aging process may contribute directly to the presentation and thus assessment of anxiety in later life. ${ }^{37}$ The detection of anxiety in the elderly can be complicated, because symptoms of anxiety can be confused with some aspects of the normal aging process, which include cognitive decline..$^{38}$ In assessing elderly patients with anxiety complaints, cognitive decline can affect the presentation of the symptoms. Agitation, for example, a common anxiety symptom among the elderly, can be the result of challenges related to memory impairment. In turn, signs of the normal aging process, such as difficulty concentrating or fatigue, can be misattributed to anxiety by older adults or clinicians. ${ }^{13}$ Again, problems with decision-making are reflected by several items of such anxiety measures, which could be endorsed due to cognitive problems with executive functioning unrelated to worry. ${ }^{39}$ In light of the complex nature of anxiety in later life, a thorough approach to assessment that considers these age-related questions is needed. As a common emotional condition, clinical anxiety should be studied in depth to increase understanding of its effects on health and quality of life. ${ }^{40-42}$ In addition, it would be important to provide insights on the co-occurrence of anxiety symptoms/disorders with depression, since rates of such comorbidity are high within older populations.

\section{Late-life anxiety assessment by self- report measures}

Self-report measures are the most common method of anxiety assessment. ${ }^{43,44}$ They are easily administered and limit patient/participant burden. About 12 anxiety self-report 
measures are commonly used for anxiety assessment in older adults. ${ }^{13}$ It is necessary to distinguish among instruments developed and validated in younger populations and measures created specifically for use with older adults. Most of the former were originally developed in college samples, and thus norms and psychometric data for older people are lacking. Of greatest interest is the question of their content validity, given that the experience and presentation of anxiety in older adults may differ from that of younger persons. ${ }^{45}$ The inclusion of somatic items could yield inflated scores and cover up differences between medical and psychological causes of anxiety. ${ }^{13}$ Therefore, providing age-appropriate norms for this population is advisable.

Moreover, instruments capable of disentangling anxiety and depression are particularly needed for the elderly. To address these limitations, some studies have investigated the psychometric properties of anxiety questionnaires in older adults (like the abbreviated Penn State Worry Questionnaire [PSWQ] and the Geriatric Anxiety Inventory - short form [GAI-SF] $){ }^{46-50}$ In addition, new instruments for older adults have been developed (eg, Adult Manifest Anxiety Scale - elderly version [AMAS-E], GAI, Geriatric Anxiety Scale [GAS]). ${ }^{17,51,52}$ Despite several advantages (eg, strong convergent validity and adequate internal consistency), modified and newly developed measures for older adults present several limitations, such as low discrimination between anxiety and depressive states or health-related variables, as well as use of dichotomous response formats, which offer less information than unidimensional ones. In addition, many measures, including items evaluating physical or sleep difficulties, exhibit poor reliability, given the difficulty to disentangle anxiety and medical factors and the high presence of sleep disturbances in later life..$^{20,27,47,52-57}$ Similarly, geriatric anxiety measures appear not to be usable for assessing anxiety in younger groups, an important challenge for researchers who investigate anxiety across the life span. While age-specific measures have their advantages, general anxiety instruments with age-based norms can be preferable to age-specific measures. From this perspective, examining the psychometric properties in measures of anxiety currently used in the elderly is useful.

\section{Aims of this review}

The aim of the present review was to analyze the psychometric properties of anxiety measures for older adults. Pertinent peer-reviewed studies were identified through keyword searches in scientific databases that target the majority of published literature in the social and medical fields (eg, PsycInfo, PubMed, Wiley Online Library, Web of Knowledge, and Google Scholar). Search terms (or word stems) consisted of ("anxiety*" [title/abstract] OR "anxiety disorder*" [title/abstract] OR "assessment*" [title/abstract] OR "psychometric properties*" [title/abstract] OR "generalized anxiety disorder*" [title/abstract]) AND ("older adults*" [title/abstract] OR “elderly" [title/abstract] OR "geriatric population" [title/abstract]), where *denoted any wild card. Manual searches of relevant peer-review journals (eg, Aging and Mental Health, International Psychogeriatrics, Psychological Assessment, Journal of Anxiety Disorders, and Psychology and Aging) were also conducted. The reference sections of the identified manuscripts were screened for additional studies. Studies considered in the current review met the following inclusion criteria: the study reported original research investigating psychometric properties (ie, factor structure, reliability, validity), the most currently used self-report measures were taken into consideration, study participants were included as both clinical and nonclinical groups, and the study was published in English. In addition, the authors included standardized questionnaires that measured the presence of general anxiety and severity of anxiety symptoms, were administered by self-report, and were set in adults aged $\geq 65$ years

To maintain brevity, the majority of the measures reviewed here were selected to provide broad coverage of general symptoms of anxiety. Self-report measures were excluded if they are intended to identify or characterize a specific Diagnostic and Statistical Manual of Mental Disorders (DSM)-5 anxiety disorder. ${ }^{58}$ Specifically, the authors excluded measures typically used to evaluate diagnostic criteria or features of specific anxiety disorders, such as panic disorder, obsessive-compulsive disorder, posttraumatic stress disorder, and others. Moreover, measures published after 1980 were excluded.

For each measure, psychometric data were investigated. Particularly, information about reliability, validity evidence based on data from clinical and nonclinical samples of older adults, and availability of age-appropriate norms were provided. Characteristics of all the seven measures of anxiety considered here are presented in Tables 1 and 2 . This information was obtained from the test manuals and the studies identified in the literature search. In this review of the scientific status of anxiety measures employed with older adults, measures that have been used frequently in the literature, thus allowing for independent replication of findings, were included. Using these criteria, the most commonly used measures to evaluate anxiety in older adults include:

- Elder-specific self-report measures of anxiety: AMAS, GAI, GAS, Worry Scale (WS) 


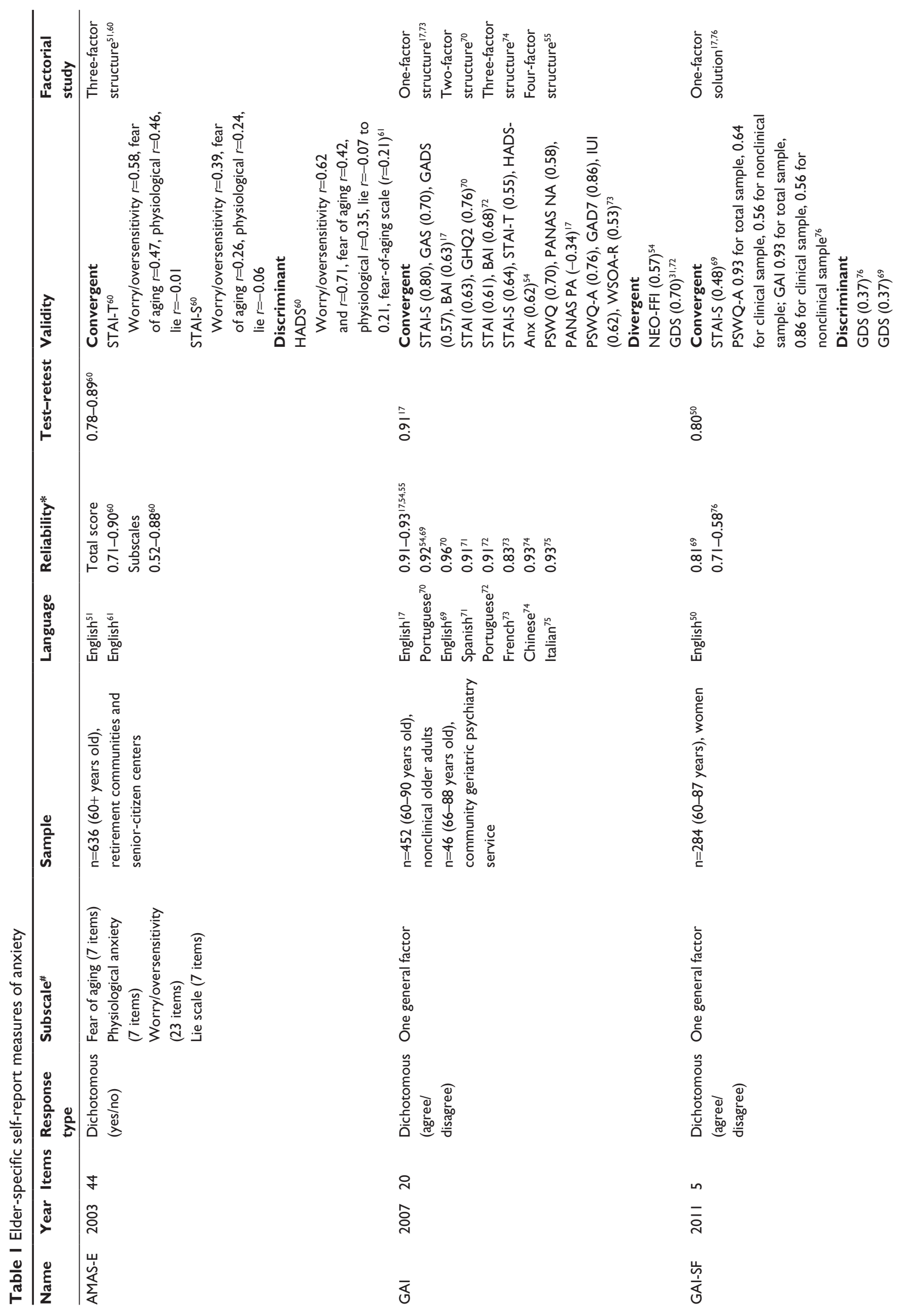




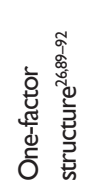

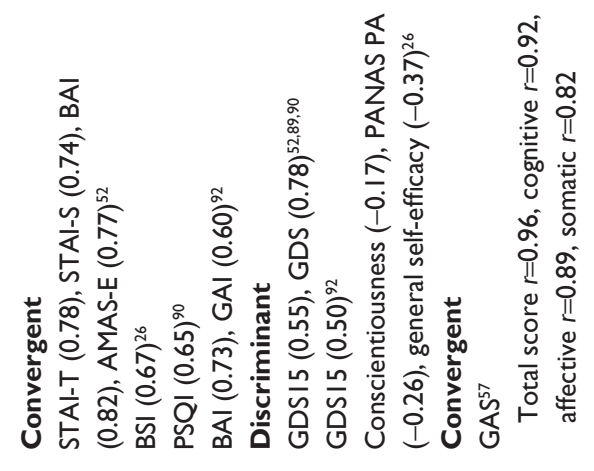

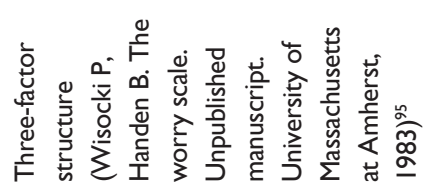

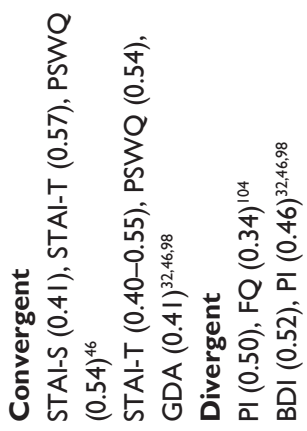

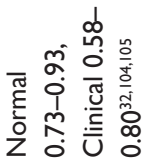

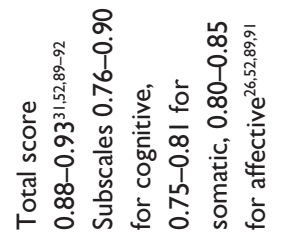

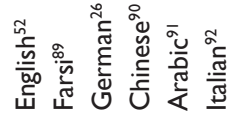
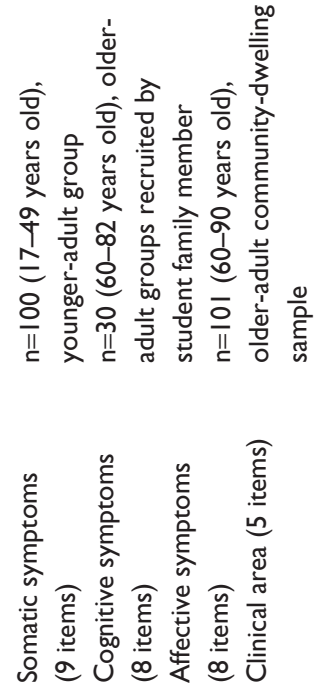

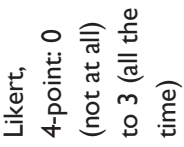

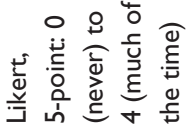

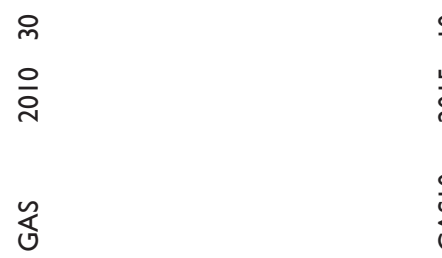

을

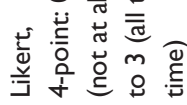

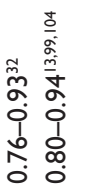

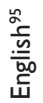

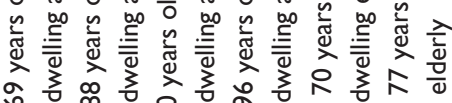

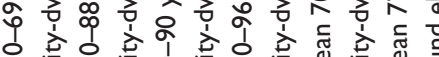

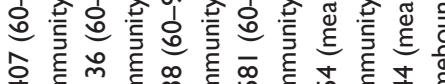

完

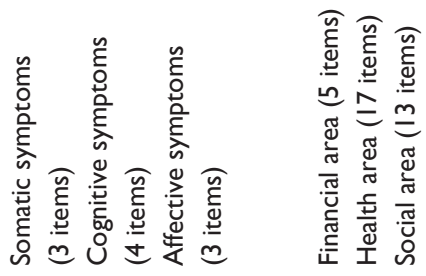

으

는

은

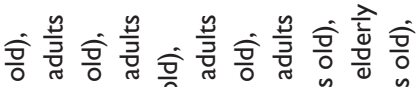

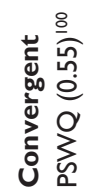

0
$\frac{0}{0}$
$\hat{\alpha}$
0
0
0
0
0
0
0

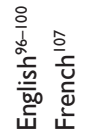
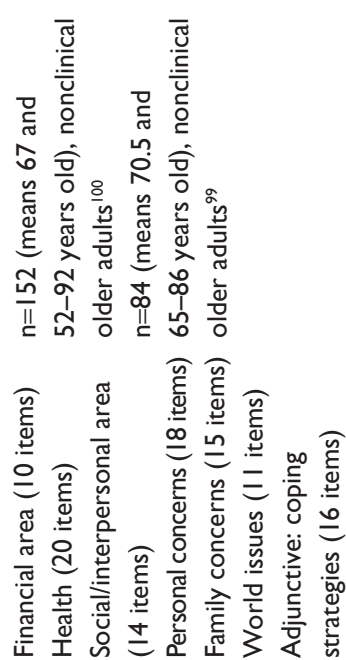

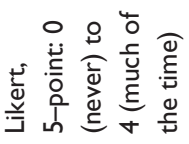

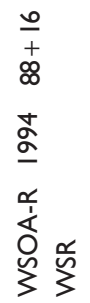

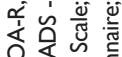

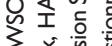

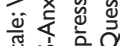

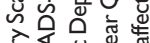

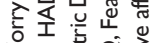

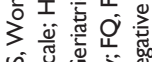

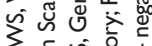

है 흥

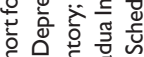

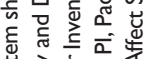

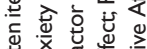

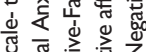

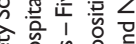

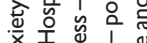

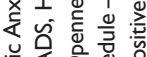

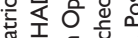

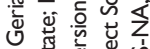

은

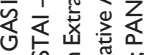

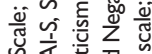

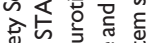

产.

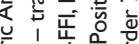

总

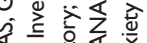

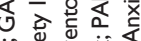

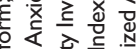

定语

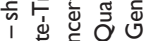

焉

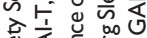

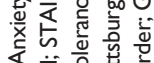

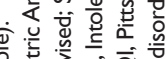

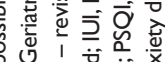

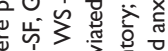

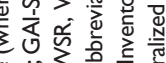

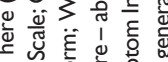

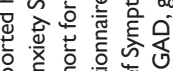

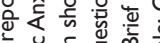

。

密

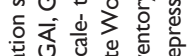

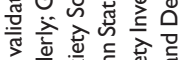

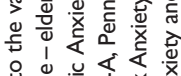

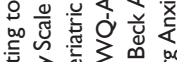

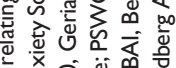

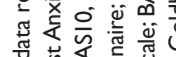

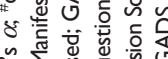

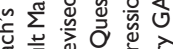

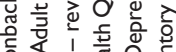

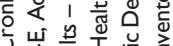

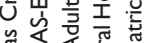

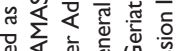

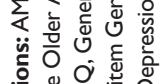

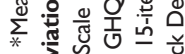

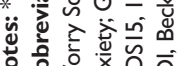




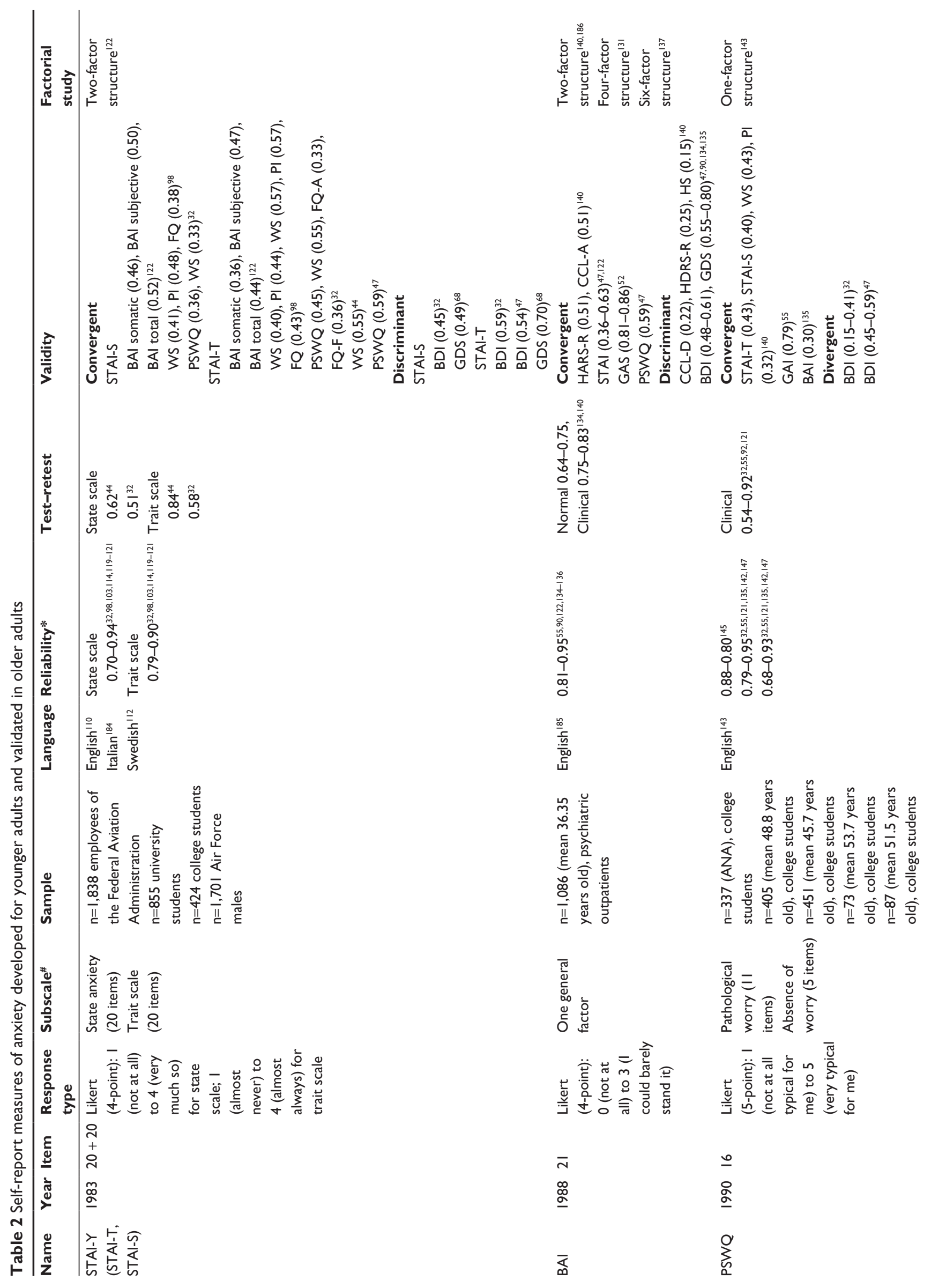



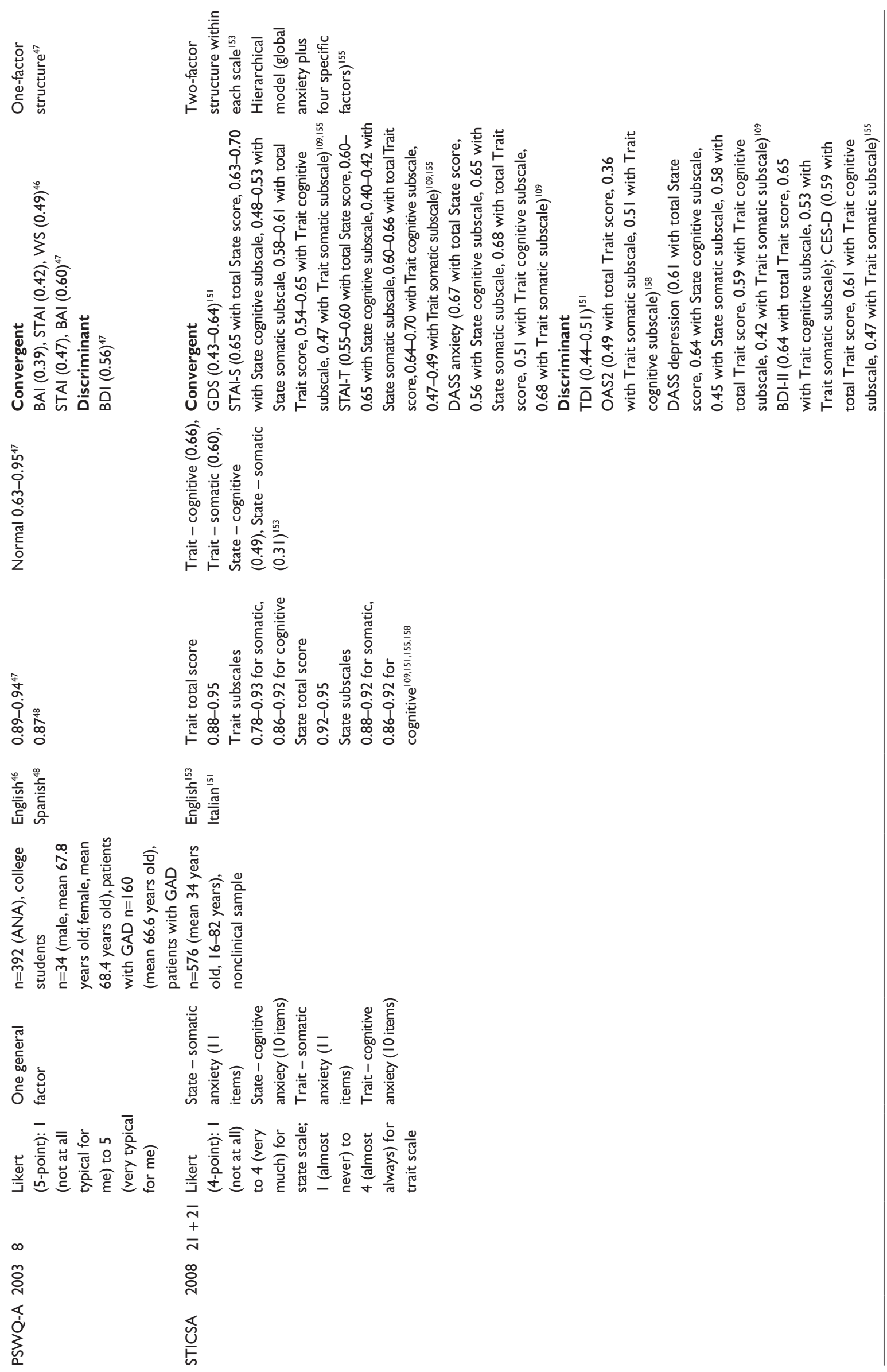

\section{,}

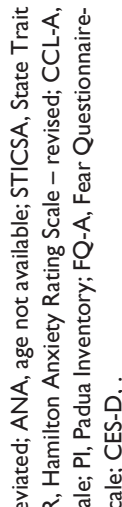

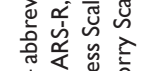

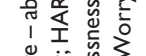

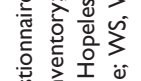

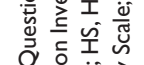

穿离

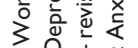

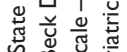

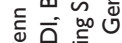

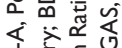

完

文

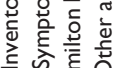

त.

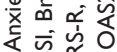

苍记

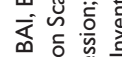

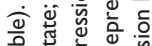

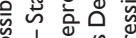

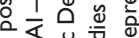

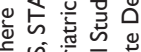

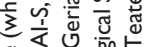

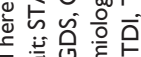

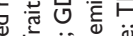

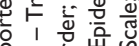

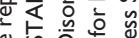

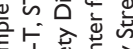

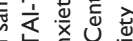

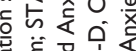

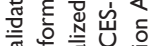

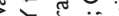

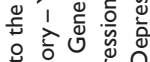

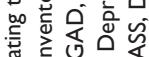

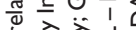

密

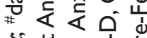

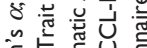

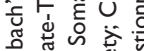

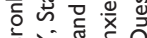

U⿱宀⿻三丨口

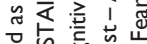

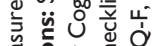

跣

$\sum_{*}^{*}$, तो

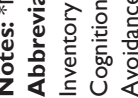


- Self-report measures of anxiety developed for younger adults and validated in older adults: State-Trait Anxiety Inventory (STAI), Beck Anxiety Inventory (BAI), PSWQ, and State-Trait Inventory for Cognitive and Somatic Anxiety (STICSA).

The aim of this review was to update findings from previous reviews on anxiety self-report measures used in older adults, ${ }^{10,13,45}$ including new measures of anxiety. Furthermore, we sought to widen psychometric information about selected self-reports presented in this review, in order to facilitate users in the choice of the most suitable instrument for their clinical or research purposes.

\section{Elder-specific self-report measures of anxiety}

\section{Adult Manifest Anxiety Scale} General characteristics

The AMAS consists of three different instruments, specifically designed for different demographic groups: the AMAS-A (for younger adults), the AMAS-C (for college students), and the AMAS-E (for older adults). ${ }^{59}$ Although the instruments do share some common items, the three versions of the AMAS were developed and normed independently. Together they have a standardization sample of 2,800 individuals, thus permitting a targeted assessment of anxiety. The AMAS-C is designed to screen and evaluate anxiety in college students. The AMAS-A is normed for individuals aged 19-59 years. It is intended for use in evaluating the level of anxiety experienced by individuals from early adulthood to late middle age. Lastly, the AMAS-E is designed to evaluate anxiety among individuals aged $\geq 60$ years. Accordingly, it includes items that identify aspects of anxiety specifically experienced by many senior citizens, such as fear of aging. ${ }^{51}$

Specifically, the AMAS-E is a 44-item self-report scale composed of a large general anxiety factor (Total Anxiety Scale), three anxiety subscales (fear of aging, physiological anxiety, and worry/oversensitivity), and a Lie scale. The fear-of-aging subscale (seven items) assesses excessive concern about the normal aging process. The physiological anxiety subscale (seven items) evaluates physical symptoms associated with anxiety, whereas the worry/oversensitivity subscale (23 items) reflects nervousness, rumination, and hypersensitivity to stress. The Total Anxiety Scale (37 items) is obtained by summing the scores from the fear of aging, physiological anxiety, and worry/oversensitivity subscales, and provides a global measure of chronic, manifest anxiety. The term "chronic, manifest anxiety" derives from a trait theory of general anxiety, and embodies the concept that anxiety can exist either as a symptom or a distinct disorder. ${ }^{51}$ The Lie scale (seven items), added at a later stage, serves as an index of the validity of the scale and measures an individual's tendency to give socially desirable responses. Respondents rate their responses on a dichotomous scale using a yes/no format, with higher scores indexing higher levels of anxiety. ${ }^{60}$ As for the other versions, AMAS-E can be administered in a group setting or on an individual basis. Typically, it takes $\sim 5-10$ minutes to complete and only a few minutes to score.

\section{Reliability}

Internal consistency reliability estimates of AMAS-E subscale scores are in the adequate-excellent range in a nonclinical population, suggesting that the item content of the subscales is relatively homogeneous and the item content of the different subscales measures meaningful dimensions associated with anxiety. ${ }^{51,60,61}$ Above all, an excellent Cronbach's $\alpha$-coefficient of $0.90-0.88$ has been found for AMAS-E Total Anxiety Scale scores for a nonclinical population. Coefficients for the three anxiety-subscale scores and the Lie scale were $0.52-0.88$ in the same population. Temporal stability estimates for AMAS-E test scores were 0.78-0.89 over a 2 -week test-retest interval in a group of 226 older nonclinical adults aged $\geq 60$ years, suggesting that the AMAS-E subscale and Lie scale scores have adequate-good test-retest reliability over a 2-week period. ${ }^{60}$

\section{Convergent and discriminant validity}

There is also evidence supporting the construct validity of AMAS-E scores as measures of various aspects of anxiety. ${ }^{60}$ Moderate validity coefficients of AMAS-E scores with STAI Trait scale scores (worry/oversensitivity $r=0.58$, fear of aging $r=0.47$, physiological $r=0.46$, lie $r=-0.01$ ) and low-moderate validity coefficients with the STAI State scale score (worry/ oversensitivity $r=0.39$, fear of aging $r=0.26$, physiological $r=0.24$, lie $r=-0.06$ ) have been reported, lending some support to the construct validity of AMAS-E scores as measures of chronic, manifest anxiety or trait anxiety.

Moderate positive correlations have been observed between the Hospital Anxiety and Depression Scale (HADS) anxiety subscale and the AMAS-E worry/oversensitivity subscales ( $r=0.62$ and $r=0.71, P<0.01$ ). The fear of aging and physiological subscales showed weak but significant $(P<0.01)$ relationships with the HADS anxiety total subscale $(r=0.42$ and $r=0.35$, respectively). A strong positive correlation was observed between the worry/oversensitivity subscale and AMAS-E total score $(r=0.90, P<0.01)$. The Lie scale showed 
a small and nonsignificant relationship with all subscales of the HADS and AMAS-E ( $r=-0.07$ to 05), except in the fear of aging scale $(r=0.21, P<0.01)$. This is indicative of the poor discriminant validity of the AMAS-E in nonclinical populations. ${ }^{61}$

\section{Factor validity}

In factor-analysis studies, a three-factor anxiety structure (fear of aging, physiological anxiety, and worry/oversensitivity) emerged. ${ }^{51,62}$ This three-factor anxiety structure is consistent with multidimensional theories of anxiety. ${ }^{63-67}$ In addition, the factor structure of the AMAS-E was examined across the sexes in a nonclinical sample of 863 older adults (555 women and 308 men) aged 60-100 years. Coefficientof-congruence and salient variable-similarity index values reported suggested that the pairs of matched factors for each of the four factors (ie, fear of aging, physiological anxiety, worry/oversensitivity, and lie) and the general anxiety or total anxiety factor were invariant across sex. ${ }^{60}$ Therefore, the same test score interpretation was supported for older nonclinical women and men.

\section{Clinical utility}

As in the other versions of the scale, the AMAS-E has a wide array of applications in general clinical practice, as well as in hospices and geriatric centers. It is a helpful instrument for clinicians who work with older adults and who are interested in monitoring their clients' treatment (both psychotherapy and drug therapy) progress. Because there are no known practice effects of responding to the scales, a clinician can track score changes over time through repeated administration. Indeed, with temporal stability coefficients reported, changes in clients' performance on the AMAS-E are more likely to be the result of treatment than errors in the measure's test scores. If the treatment is effective, AMAS scores should decrease. If scores remain high, alternative treatments should be considered. ${ }^{51}$

\section{Geriatric Anxiety Inventory}

\section{General characteristics}

The GAI is a self-report scale consisting of 20 dichotomous items (agree/disagree), modeled after the Geriatric Depression Scale (GDS). ${ }^{17,68}$ Items originated from an initial item pool of 60, based on a large variety of anxiety instruments, in order to reflect the primary domains of anxiety (such as worry, anxiety sensitivity, and cognition about anxiety) in older adult populations. The final 20 -item GAI presents a strong content emphasis on aspects of worrying and less emphasis on somatic symptoms of anxiety. Although less useful to indicate gradations of symptom severity, ${ }^{26}$ its dichotomous response format appears to be easy for mildly cognitively impaired older adults, eg, in nursing-home settings. The GAI-SF is composed of five items (items 1, 6, 8, 10 , and 11 of the long version), selected to allow quicker administration. ${ }^{50}$ For both versions, the total score is calculated by summing the score of each item ( 0 or 1$)$. Higher scores suggest higher anxiety. The range of variation is $0-20$ for the GAI and 0-5 for the GAI-SF. The GAI was developed and normed with both healthy adults from the general population and psychogeriatric patients.

\section{Reliability}

Internal consistency for the GAI total score was excellent (with Kuder-Richardson 20 coefficients of 0.91-0.93). ${ }^{17,54,55}$ In addition, 0.92 was attained with Australian communityresiding older women, ${ }^{69} \alpha=0.96$ with a Portuguese sample of 152 community-dwelling older adults, ${ }^{70} \alpha=0.91$ with Spanish community-dwelling older adults, ${ }^{71} \alpha=0.91$ with a psychogeriatric sample and healthy older community-dwelling subjects, ${ }^{72} \alpha=0.83$ with older French Canadian communitydwelling adults, ${ }^{73} \alpha=0.93$ with older Chinese adults from the general population, ${ }^{74}$ and $\alpha=0.93$ with older Italian patients. ${ }^{75}$ Test-retest reliability was good $(r=0.80) .{ }^{50}$ As regards GAISF's internal consistency, values were good in a sample of older community-residing women $(\alpha=0.81) .{ }^{50}$ A recent study showed adequate value for a nonclinical sample $(\alpha=0.71)$, but marginal value for a clinical sample $(\alpha=0.58){ }^{76}$

\section{Convergent and divergent validity}

Evidence for convergent validity of GAI scores has been confirmed by high correlations $(P<0.001)$ with anxiety measures, such as STAI-S $(r=0.80)$ and GAS $(r=0.70)$ in a geriatric psychiatry sample and Goldberg Anxiety and Depression Scale $(r=0.57, P<0.001)$ and BAI $(r=0.63, P<0.001)$ in a nonclinical sample; ${ }^{17}$ STAI $(r=0.63, P<0.001)$ and General Health Questionnaire (GHQ) $(r=0.76, P<0.001)$ in both a clinical and nonclinical sample; ${ }^{70}$ STAI $(\rho=0.61, P<0.001)$ and BAI $(\rho=0.68, P<0.001)$ in a nonclinical Portuguese sample $;{ }^{72}$ STAI - state $(\rho=0.64, P<0.001)$, STAI - trait $(\rho=0.55$, $P<0.001)$, HADS - anxiety $(\rho=0.62, P<0.01)$ in a nonclinical Italian sample; ${ }^{75}$ worry measures, such as PSWQ $(r=0.70, P<0.001)$, Positive and Negative Affect Schedule negative $(r=0.58, P<0.001)$, and Positive and Negative Affect Schedule - positive $(r=-0.34, P<0.001)$ in a clinical sample ${ }^{17}$ and PSWQ-A $(r=0.76, P<0.001)$, Generalized Anxiety Disorder (GAD)-7 ( $r=0.86, P<0.001)$, Intolerance 
of Uncertainty Inventory ( $r=0.62, P<0.001)$, and WS Older Adults - revised (WSOA-R; $r=0.53, P<0.001$ ) in a nonclinical French sample, ${ }^{73}$ and general measures, such as Neuroticism Extraversion Openness Five-Factor Inventory ( $r=0.57$, $P<0.001)$ in a sample of community-residing women ${ }^{69}$ and GDS $(\rho=0.70, P<0.001)$ in a nonclinical sample..$^{31,72}$

With regard to the GAI's discriminant validity in a nonclinical population, Yochim et al found a higher and significant relationship ( $r=0.74, P<0.01$ ), but they did not find a significant correlation between the GAI and medical burden. ${ }^{31}$ Byrne et al found that poorer general health was associated with higher GAI scores $(r=-0.28, P<0.01)$ in a female nonclinical sample. ${ }^{69}$ Also, significant $(P<0.01)$ associations between all GAI factors and total score with rumination (GAI total score, $r=0.55$; GAI cognitive symptoms, $r=0.55$; GAI arousal symptoms, $r=0.42$; GAI somatic symptoms, $r=0.35$ ) and experiential avoidance (GAI total score, $r=0.39$; GAI cognitive symptoms, $r=0.38$; GAI arousal symptoms, $r=0.26$; GAI somatic symptoms, $r=0.31$ ) have been found in a sample of older adults living in a Spanish community. ${ }^{71}$ Though the ability of this instrument to disentangle anxiety and depression symptoms is limited, this issue is not very different from what characterizes other geriatric measures in adult samples. ${ }^{32}$ Researchers have attempted to explain comorbidity through a partial overlapping of psychological and neurological bases of anxiety and depression. ${ }^{77-83}$ Others have argued that a unitary factor of "distress" that comprises mixed anxiety and depression among older adults might exist. ${ }^{30}$ Consequently, the diagnostic criteria of both disorders do overlap to some degree. As regards the GAI-SF, several studies have investigated construct validity. Concerning convergent validity in a nonclinical sample, this instrument presented $r=0.48(P<0.001)$ with the STAI-S. ${ }^{50}$ Johnco et al showed moderate-high significant correlations between the PSWQ-A ( $r=0.93$ for total sample, $r=0.64$ for clinical sample, and $r=0.56$ for nonclinical sample) and GAI. As regards discriminant validity, the instrument exhibited significant $r$-value of $0.37(P<0.001)$ compared to the GDS..$^{50,76}$

\section{Factor validity}

Factor analyses (both exploratory and confirmatory) have postulated the unidimensional nature of the scale in original version. ${ }^{17,73}$ However, in the Portuguese version 2, distinct components were postulated, ${ }^{70}$ whereas in the Chinese version 3 factors were postulated. ${ }^{74}$ Also, a four-factor structure of the instrument emerged. ${ }^{84} \mathrm{~A}$ unidimensional nature has also been found for the GAI-SF. ${ }^{50,76}$

\section{Clinical utility}

The GAI has been used in multiple health care settings, including ambulatory clinics, inpatient wards, and domiciliary services. ${ }^{55,85}$ It is considered to exceed the GAS in identifying the presence of anxiety disorders. ${ }^{20}$ Authors identified a clinical cutoff score $>8$ to detect the presence of any anxiety disorder in geropsychiatric patients ${ }^{17}$ and older homebound adults. ${ }^{17,55,84}$ With regard to the assessment of effects of mental health treatments in older adults, Kneebone et al underlined the GAI's validity and reliability in screening for anxiety after stroke in older patients. ${ }^{86}$ Bendixen et al used the GAI to analyze anxiety symptoms in older adults with depression, dementia, or psychosis, and found higher anxiety scores in depressed patients. ${ }^{87}$

Regarding cognition, the GAI has been administered for assessing anxiety in older patients with a range of memory abilities, including those from a memory clinic and in longterm care. ${ }^{54,85}$ The GAI's factor structure has been investigated in patients with dementia, cognitive impairment, and no impairment, ${ }^{84}$ but studies have not identified whether cognitive abilities affect the GAI's psychometric properties in a largely unimpaired sample or whether its psychometric properties depend on participants' memory ability. Recently, Gould et al documented decreased psychometric performance for average-memory compared to superior-memory subjects in a sample of older community-dwelling adults. ${ }^{39}$

\section{Geriatric Anxiety Scale}

\section{General characteristics}

The GAS is a 30-item self-report screening and assessment tool specifically designed for use with older adults. ${ }^{52}$ Of the 30 items, the first 25 are scorable, assessing experienced symptoms of anxiety, and the remaining five items investigate specific content areas of anxiety often reported to be of concern for older adults (eg, health and financial concerns, fear of dying). These latter five items are for clinical use, and as such are not included in the GAS total score. ${ }^{52}$ Individuals are asked to indicate how often they have experienced each symptom in the last week, including that day. Respondents answer using a 4-point Likert scale ranging from 0 (not at all) to 3 (all of the time), with higher scores indicating higher levels of anxiety.

The GAS includes three subscales tapping into common components of anxiety: somatic symptoms (nine items), cognitive symptoms (eight items), and affective symptoms (eight items). It is based on the full range of anxiety-disorder symptoms included in the DSM-IV-TR ${ }^{88}$ The GAS has been 
normed with samples of older community-dwelling adults and translated into many languages: Farsi, ${ }^{89}$ German, ${ }^{26}$ Chinese, ${ }^{90}$ Arabic,${ }^{91}$ and Italian..$^{92}$ Moreover, the GAS10 has recently been developed, identifying 10 items with the highest-discrimination parameters while retaining the structure of the subscales. ${ }^{92}$ It also presents promising psychometric characteristics. ${ }^{57}$

\section{Reliability}

Internal consistency reliability for GAS and GAS10 total scores were excellent $(\alpha=0.88-0.93$ ) in a nonclinical population of older adults. ${ }^{26,31,52,57,89-92}$ According to several studies, internal consistency for subscale scores ranged from good to excellent among community-dwelling populations of older adults, with $\alpha=0.76-0.90$ for the cognitive subscale, $0.75-0.81$ for the somatic subscale, and $0.80-0.85$ for the affective subscale. ${ }^{26,52,89,91}$

\section{Convergent and discriminant validity}

Strong associations with anxiety measures have demonstrated the convergent validity of GAS scores. Segal et al found significant $(P<0.01)$ correlations between the GAS and the STAI Trait scale $(r=0.79),{ }^{52}$ the STAI State scale $(r=0.74)$, the BAI $(r=0.82)$, and the AMAS-E $(r=0.77)$ in a nonclinical population of older adults. Recent studies have shown this instrument to be highly correlated with the anxiety scale of the Brief Symptom Inventory ${ }^{93,94}$ and the Pittsburg Sleep Quality Index $(r=0.67, P<0.001 ; r=0.65$, $P<0.001$; respectively). ${ }^{26,90}$ Regarding discriminant validity, GAS total score was significantly correlated with the GDS15 $(r=0.55, P<0.001)$ and with GDS $r$-value of 0.78 $(P<0.01$ and $P<0.001)$ in a nonclinical population. ${ }^{52,89,90}$ Moreover, correlation coefficients for GAS subscale and depression scores vary noticeably and significantly $(P<0.01)$, from $r=0.53$ (somatic) to 0.82 (cognitive), denoting better discriminant validity for the GAS somatic subscale compared to the cognitive and affective subscales. ${ }^{52}$ As seen before, discriminant validity was limited based on significant associations with depression instruments, as well as with conscientiousness $(r=-0.17, P<0.05)$, positive affect $(r=-0.26$, $P<0.001)$, and general self-efficacy $(r=-0.37, P<0.001) .{ }^{26}$ A recent Italian study showed significant and substantial positive correlations between the GAS and BAI ( $r=0.73$, $P<0.001)$ and the GAI $(r=0.60, P<0.001)$, and low but significant correlation with the $\operatorname{GDS} 15(r=0.50, P<0.001) .{ }^{92}$ The GAS10 showed good reliability and convergent and factorial validity. Specifically, GAS10 internal consistency was 0.89 , and $r$-values with the GAS long form were significantly high ( $r=0.96, P<0.001$ with GAS total, $r=0.92, P<0.001$ with GAS cognitive, $r=0.89, P<0.001$ with GAS affective, and $r=0.82, P<0.001$ with GAS somatic). ${ }^{57}$

\section{Factor validity}

With regard to factor structure, the unidimensionality of the GAS in the original US sample was confirmed and compared with the originally proposed three-factor structure of the GAS using a confirmatory factor-analysis approach. ${ }^{26,89-91}$ The unidimensionality of the GAS, which meant that all GAS items appeared to tap the same underlying latent construct (ie, general anxiety), ${ }^{57}$ is not surprising, given the already mentioned co-occurrence of different aspects of anxiety. Gatti et al found a unidimensional structure to the Italian version of the GAS, in accordance with other validated versions. $^{92}$ Therefore, special care should be taken when interpreting subscale scores, as they do not appear to be clearly distinguishable from one another.

\section{Clinical utility}

Regarding cognition, GAS scores have not been found to be strongly associated with reading ability or processing speed in older community-residing adults. ${ }^{31}$ Additionally, recent studies reported low discriminant validity of the GAS in older adults with memory impairment, consistent with elevated levels of anxiety symptoms in patients with cognitive deterioration compared to those with normal cognition. ${ }^{20,84}$ Psychometric performance characteristics of the GAS have been found to be decreased in subjects with average delayed memory recall compared with those with superior recall. ${ }^{20}$

By using receiver operating characteristic analysis, a GAS cutoff score $>16$ has been identified as optimal at the $P<0.01$ level based on an efficiency of $89 \%$ (ie, the percentage of correctly classified participants) in the US sample. However, it could not be adjusted on the balance of sensitivity and specificity, which was optimized with a cutoff score $>9$. If clarified in larger clinical samples, the detection of a clinical cutoff score for the GAS could enhance its applicability in research and clinical settings. ${ }^{20}$

\section{Worry Scale \\ General characteristics}

The WS is a self-report questionnaire generated specifically for use with older adults. ${ }^{95,96}$ Two versions of this scale have been developed: the WS and its extension, the WSOA-R. ${ }^{97}$ The first consists in 35 items that assess financial, health, and 
social worries commonly associated with aging. These areas represent the three subscales of the instrument (composed of five items for financial, 17 for health, and 13 for social), which provide a total score ranging from 0 (lower level of worry) to 140 (higher level of worry). Items are rated on a 5-point Likert scale ranging from 0 (never) to 4 (much of the time), and the sum of all answers represents the total score. No norms or cutoffs were provided in the original study. Stanley et al found a mean score of 35.4 in a sample of older adults with generalized anxiety disorder, ${ }^{98}$ while Wisocki found mean scores of 10.4-17.4 in a community sample of active older adults and 17.3-23.7 in samples of homebound older adults. ${ }^{96} \mathrm{~A}$ mean of 11 has been found in a nonclinical sample. ${ }^{98}$ The revised and expanded version of WS, the WSOA-R, has been developed and validated in older adults. ${ }^{96,99}$ It consists of 88 items and includes six dimensions: finances (ten items), health (20 items), social/interpersonal (14 items), personal concerns, such as crime or psychological problems (18 items), family concerns (15 items), and world issues (eleven items). Each item is presented on a 5-point Likert scale ranging from 0 (never) to 4 (much of the time). ${ }^{96}$ The possible total score is $0-352$. Differently from the WS, the WSOA-R includes a separate 16 items that assess coping strategies used to control worry. ${ }^{99}$ No norms or cutoffs were provided in the original study. Hunt et al showed a mean of 154.57 in a sample of nonclinical older adults. In both scales, participants respond to each item by indicating how much they worry about that topic. ${ }^{100}$

\section{Reliability}

Both versions generally show adequate validity and reliability with older adults. ${ }^{13,99,101,102}$ Regarding the original version, a few studies have examined its psychometric characteristics in the elderly. ${ }^{103}$ Stanley et al highlighted that this instrument demonstrated adequate internal consistency in a sample of older adults with well-diagnosed generalized anxiety disorder $(\alpha=0.76-0.93),{ }^{32}$ and good-excellent internal consistency for subscale and total scores in a nonclinical subsample has also been indicated ( $\alpha=0.80-0.94){ }^{13,99,104}$ Indeed, test-retest reliability is adequate for clinical $(r=0.73-0.93)$ and nonclinical groups ( $r=0.69-0.80)$, except for health concerns $(r=0.58) .{ }^{98}$ Another study showed adequate test-retest reliability values ( $r=0.70-0.77)$, except for the social subscale $(r=0.58)$ in a clinical sample. ${ }^{32,105}$ As regards the psychometric proprieties of the WSOA-R, they are currently under investigation, and very few studies have tested them. ${ }^{13}$ The instrument shows high reliability of $0.88-0.97$ and subscales are strongly correlated $(r=0.47-0.80) .{ }^{99,100}$ In a recent study, Litwin and Meir highlighted an internal reliability of $\alpha=0.90$ for the financial worry component. ${ }^{106}$

\section{Convergent and discriminant validity}

As for convergent validity, several studies have shown good correlations between this instrument and other measures of anxiety in nonclinical samples, like the STAI-S ( $r=0.41$, $P<0.001)$, the STAI-T $(r=0.57, P<0.001)$, and the PSWQ $(r=0.54, P<0.01) .{ }^{46}$ Convergent validity has also been tested in samples of older adults with generalized anxiety disorder, showing moderate correlations with the STAI-T ( $r=0.40-0.55, P<0.001$ and $P<0.01$ ), the PSWQ ( $r=0.54$, $P<0.001)$, and the GDS $(r=0.41, P<0.01)$ scales. No significant correlation has been found with the STAI-S scale. ${ }^{32,46,98}$ Divergent validity has been studied in both nonclinical and clinical samples. In a population of nonclinical older adults, the instrument showed low correlations with the Padua Inventory $(r=0.50, P<0.001)$ and with the Fear Questionnaire (FQ) $(r=0.34, P<0.001) .{ }^{104}$ Nonsignificant correlations have been found with the FQ, while low or moderate but significant $(P<0.01)$ correlations with the BDI $(r=0.52-0.54)$ and the Padua Inventory ( $r=0.46)$ have been shown in clinical samples. ${ }^{32,46,104}$ As regards the WSOA-R, no values have been reported for the construct validity. ${ }^{106}$

A three-factor structure has been found for the WS.95,98,107 No studies on the factor validity of the WSOA or WSOA-R have been found to date. ${ }^{96,97}$ Few studies have used the WS to assess the efficacy of treatment in older adults with generalized anxiety disorder. Stanley et al compared the efficacy of cognitive behavior therapy and supportive psychotherapy in a sample of older adults with well-diagnosed generalized anxiety disorder, using a wide range of instruments assessing anxiety, among them the WS. ${ }^{104}$ They found that on the WS, no change was evident over treatment, but scores demonstrated significant improvement over follow-up. A very recent study about the effectiveness of psychological interventions (cognitive behavior therapy, psychodynamic interpersonal therapy, therapeutic conversations, and counseling) in reducing anxiety in older persons with cognitive deterioration (dementia or mild cognitive impairment) confirmed those results. ${ }^{108}$

\section{Self-report measures of anxiety developed for younger adults and validated in older adults}

Several other measures of anxiety have been specifically developed for younger population and then validated in older populations. They also present strong psychometric properties (Table 2). 


\section{State-Trait Anxiety Inventory}

The STAI, one of the best-known and most widely used selfreport questionnaires to measure anxiety, has appeared in over 3,000 studies and is available in over 30 languages. ${ }^{66,109}$ The instrument is composed of two scales with 20 items each to provide separate measures of "state" (STAI-S; how people feel right now) and "trait" (STAI-T; how people generally feel) anxiety. In addition, the 20 items for each scale can also be divided into two other groups to measure present-absent continuum anxiety. ${ }^{110,184}$ The total scale score ranges from 20 (low anxiety) to 80 (high anxiety) for each single scale. A cutoff score of 39/40 is used to identify clinically significant symptoms of anxiety in a nonclinical sample. ${ }^{111-113}$ In a clinical sample with anxiety or mood disorders, the normative cutoff is $44-53 .^{32,114-116}$ Cutoff scores of $44 / 45$ have been found in a sample of normal older adults. ${ }^{117-119}$ The STAI has shown excellent values of internal coherence but insufficient test-retest reliability for the state and trait scales in nonclinical older adults ${ }^{104}$ and a clinical sample, respectively. ${ }^{32,44,103,114,119-122}$ Concerning validity, low-moderate correlations between the STAI and other measures of anxiety, worry, and depression have emerged in several studies ${ }^{44}$ Limited discriminant validity has also been shown for both state and trait scales of the STAI. The STAI has been used extensively in a number of chronic medical conditions. ${ }^{123-126}$

Few studies have addressed the predictive use of the STAI to evaluate eventual improvements due to mental health treatment for older adults..$^{32,44,105}$ Results have shown three consistent limits of the STAI: it does not discriminate between anxiety and depression, it is lengthy and easy to misinterpret, it assesses a general negative affect. . $^{4,127-129}$ The weak discriminant and factorial validity suggests that the STAI should be used with caution in old/middle-age populations. . $^{10,13,43,114,122}$

\section{Beck Anxiety Inventory}

Another well-established screening instrument for measuring the severity of anxiety is the BAI ${ }^{26}$ The BAI is a self-report questionnaire composed of 21 items drawn from three preexisting scales (the Anxiety Checklist, the Physician's Desk Reference Checklist, and the Situational Anxiety Checklist) to obtain a purer measure of anxiety that is independent of depression symptoms ${ }^{130}$ and sensitive to treatment change. ${ }^{131}$ Each item describes cognitive and somatic symptoms (eg, panic-related or subjective symptoms like nervousness, fear of losing control). ${ }^{122} \mathrm{~A}$ single total score ranges from 0 (low anxiety) to 63 (high anxiety). Four cutoff scores have been provided by authors in the manuals: 0-7 (normal anxiety), 8-15 (mild-moderate anxiety), 16-25 (moderate-severe anxiety), and 26-63 (severe anxiety). However, these cutoffs do not specifically refer to an older adult population. ${ }^{13,44,132,133}$ The BAI has not been found to be responsive to change over time in clinical older adults. ${ }^{122}$ Despite this, the BAI has been used extensively with populations of older adults, and several studies have investigated its psychometric properties in this population. ${ }^{13,44,185,186}$ Internal reliability was good-excellent both for clinical and nonclinical samples, ${ }^{55,90,122,134-136}$ with scores increasing slightly with age. ${ }^{10,137}$ Adequate-good testretest reliability has been found in anxiety patients ${ }^{138,139}$ and nonclinical older adults. ${ }^{55,140}$ Concerning construct validity, the BAI shows modest correlations with other anxiety and relatively high values with depression measures. Overall, its discriminant validity is limited.

\section{Penn State Worry Questionnaire}

Support for psychometric properties of the PSWQ in anxious and nonanxious sample of older adults has been found in different studies. ${ }^{32,121,141,142}$ The PSWQ is composed of 16 items used to assess a person's general tendency to worry. ${ }^{143}$ Specifically, it evaluates pathological worry, with a single total score ranging from 16 (low worry) to 80 (high worry). The PSWQ has been validated and tested in a sample of undergraduates, but it has also been used with older adults. ${ }^{143-145}$ A cutoff score of 50 has been found for use with a sample of older adults with generalized anxiety disorder. ${ }^{105}$ Overall, the authors highlighted the problematic aspect of the PSWQ related to the difficulties of some older adults to complete and interpret the content of the reversed items. ${ }^{105,146}$ For all these reasons, a reduced form of the PSWQ with eight items has been proposed: the PSWQ-A. ${ }^{46}$ Compared to the full form, the PSWQ-A may be useful in assessing worry in older adults. ${ }^{13}$ As regards its psychometric properties with older adults, the PSWQ and PSWQ-A show adequate internal consistency and test-retest reliability in clinical, ${ }^{32,55,121,135,142,147}$ older community-dwelling adults, ${ }^{47,48}$ and nonclinical samples. ${ }^{141,144,145,148}$ As for construct validity, the PSWQ and PSWQ-A show moderate-adequate convergent validity in both clinical and nonclinical older adults. ${ }^{46,47}$ Concerning its clinical efficacy, several studies have shown that the PSWQ was a useful predictor of clinician-rated generalized anxiety-disorder severity. ${ }^{43,142,149,150}$ In sum, despite the high internal consistency estimate, the minimal evidence of PSWQ construct validity represents a strong limitation for applicability with older adults. 


\section{State-Trait Inventory for Cognitive and Somatic Anxiety}

A new measure of anxiety developed for a younger population with good chances of being applied to older adults ${ }^{151,152}$ is the STICSA. The STICSA is a self-report questionnaire designed to assess somatic and cognitive symptoms of anxiety. ${ }^{153}$ This instrument was generated to improve limitations of the STAI (eg, weak structure, capacity to distinct anxiety symptoms from depression). ${ }^{44,127-129,154}$ However, the STICSA replicates the STAI's format on independent state ("How do you feel right now, at this very moment, even if this is not how you usually feel?") and trait ("How often, in general, is this statement true of you?") scales, and was based on Spielberger's theoretical formulation of state-trait anxiety ${ }^{66}$ It consists of 21 items for each scale.

Both the STICSA state and trait scales contain two subscales. One scale measures the cognitive symptoms of anxiety, and the second reflects the somatic symptoms of anxiety. Accordingly, it is composed of four subscales: state - somatic, trait - somatic, state - cognitive, and trait cognitive. Each scale provides an independent score, and the sum of these gives a total score. Low values correspond to low anxiety, while high values correspond to high anxiety. A cutoff of 43 for the total score was found to detect pathological state or trait anxiety, but no older adults were studied. ${ }^{153}$ Few studies have investigated its psychometric properties in a sample of older adults. A recent study showed how the STICSA has good psychometric properties in a nonclinical sample of older adults. Concerning reliability, all STICSA subscales have excellent internal consistency. ${ }^{109,151,153,155}$ All STICSA subscales showed good convergent and divergent validity, with medium to high correlations in relation to other anxiety (ie, GDS, STAI) and depression measures (ie, TDI). ${ }^{156-159}$ According to the authors, the STICSA is a promising measure of general anxiety since it provides a more specific assessment of cognitive and somatic anxiety symptoms among older adults.

\section{Conclusion}

Despite relatively high prevalence rates, little is known about the experience, phenomenology, and assessment of anxiety in later life. Kogan et al suggested that “... assessment of anxiety in older adults is in its infancy". ${ }^{10}$ For this reason, it is reasonable to assume that the current estimates of prevalence of anxiety disorders in late life are underestimated and thus slightly lower than those for younger adults $(5.5 \% \mathrm{vs}$ 7.3\%). ${ }^{4,40,160}$ Ultimately, anxiety disorders occurring among older adults are more likely to go unnoticed and untreated relative to anxiety in younger populations. As the prevalence of clinical and subclinical anxiety increases in later life, evidence-based assessment instruments will be increasingly important for use in settings in which older individuals require mental health services.

This review aims to upgrade the knowledge into the development and standardization of psychometrically sound assessment instruments of anxiety in older adults. Empirically supported assessment tools are scientifically valid and increasingly needed in both clinical practice (to evaluate patient level of functioning and to monitor treatment outcome) and in the research context (to select research participants and evaluate therapeutic choices) ${ }^{8}{ }^{8161}$ Guidelines for choosing the best instruments that emphasize the importance of solid psychometric properties, adequate age-relevant norms, and evidence of clinical utility could be of great help to the clinician and the researcher, as well as in developing evidence-based mental health services to older adults.

The detection and assessment of anxiety among the elderly is very complicated, because symptoms of anxiety can be confused with some aspects of the normal aging process, which include cognitive decline, ${ }^{38}$ as well as with high medical and mental comorbidities, ${ }^{10}$ with depression as the most common comorbid disorder of anxiety disorders. ${ }^{162}$ Additionally, assessing anxiety in older adults by self-report measures can be particularly risky, because of age differences in the experiences of affect or interpretation of affective terms compared with younger people. ${ }^{14}$ Providing an updated state of the art of self-report measures of anxiety in the elderly can be helpful in examining the psychometric performance properties of the most commonly used anxiety self-report measures and evaluating the soundness of these measures for clinical and research use with older adults.

Some critical aspects emerge from the evaluation of anxiety in a geriatric population. The first critical consideration is the scarcity of measures specifically developed for this population. Of the instruments taken into consideration in this review, only half were specifically designed for older adults. The others (STAI, BAI, PSWQ, and STICSA) were originally developed for younger adults and then adapted for the geriatric population, presenting modest content-validity evidence. Indeed, assessing anxiety among older adult populations by self-report measures presents numerous additional critical issues compared with younger populations, such as the ability to distinguish between anxiety-like symptoms caused by a (more present) medical condition from symptoms caused by an anxiety disorder, a tendency to report more somatic symptoms, the more frequent coexistence of anxiety 
and depression in later life, the high comorbidity of anxiety with greater disability, even in high-functioning older adults, and diminished quality of life, ${ }^{163}$ and the presence of more harmful health consequences of anxiety, including increased risk of death by suicide. ${ }^{164,165}$

Based on the examination of these age-related factors, it is reasonable to argue that the anxiety measures considered here, like the BAI, STAI, STICSA, and PSWQ, have greater limitations for use with older adults than the elder-specific measures, like the AMAS-E, GAI, GAS, and WS. For instance, among the measures developed in younger samples included in this review, the BAI seems to be weighted heavily with self-reported somatic symptoms, which makes it difficult to distinguish between anxiety symptoms and symptoms resulting from other health problems. The potential overlap between physical disease and anxiety is a critical issue for clinicians and researchers, because anxiety and medical problems can have a reciprocal influence and in turn impact the assessment process, reducing the discriminant validity of anxiety measures from health-related variables. ${ }^{166}$ Consequently, the BAI appears to be a poor choice for use with medically ill older adults seen in primary-care settings or receiving home care. ${ }^{84,167}$ Similarly, the PSWQ results rely heavily on reverse-scored items, which makes completion by some older adults difficult, as well as the interpretation of its content by clinicians and psychometrists, given they load on separate factor. ${ }^{46}$ This results in diminished reliability and validity of this scale.

The second critical consideration concerns the length of the scale, a relevant empirical issue that should be addressed when assessing clinical variables among older adult respondents. Indeed, short versions of assessment instruments should be preferred in busy clinical settings and lengthy research protocols to reduce the burden of administration time and scoring, especially for some older subjects, in order to reduce possible fatigue from longer assessments. ${ }^{57}$ Within the item-response-theory framework (ie, a set of statistical models used to measure latent variables that posits that responses on a given item are a function of both person and item properties), ${ }^{168,169}$ short forms of assessment instruments could be created by identifying and retaining the items that provide the greatest information and have the highest discrimination parameters while maintaining the integrity of the subscales, as Mueller et al did with the GAS10. ${ }^{57}$ It was expected that the short form would have adequate reliability and function similar to the full-length forms.

The third critical consideration is based on the limited availability of updated investigations about the psychometric performance properties of these instruments. Studies have highlighted adequate values for internal consistency for all measures ( $\alpha=\geq 0.70$ ), but most came from a single published study with no replication or extension. For example, few studies have investigated the psychometric properties of the WSOA-R (Wisocki P. Worry scale - revised. Unpublished manuscript. University of Massachusetts, 2000). ${ }^{96}$ Until sufficient psychometric evidence is available for the use of this instrument, researchers and clinicians should proceed with caution with its use. On the contrary, the STAI has a consistent number of studies that have investigated its psychometric properties, but most are dated. ${ }^{66,111,112,114,122}$ In some studies examining psychometric soundness of these assessment instruments, relevant methodological shortcomings have been found, such as restriction of age ranges, small samples, homogeneity of samples, and lack of ethnic and educational diversity within the samples. ${ }^{10}$

In other studies, no measurement-item bias (which occurs when a certain group of subjects has an unequal chance of endorsing an item than another group of individuals, despite being matched upon the variable) have been taken into consideration in scale construction, although age and sex appear to have an impact upon the incidence of anxiety in late life. Definitely, further accurate and updated studies, even within the Item Response Theory framework, ${ }^{170-173}$ should be conducted to examine closely the item properties of the anxiety measures in the later life if clinicians are to use these measures with confidence in older adults. More importantly, given the increasing diversity that will be manifested in upcoming cohorts of older adults, future research should examine the psychometric characteristics of the assessment tools in culturally diverse populations of older adults. ${ }^{57,174,175}$ Concurrently, researchers should pursue culturally sensitive translations of these measures into other languages. ${ }^{57}$

The fourth consideration deserving consideration concerns the construct validity of the anxiety measures considered. Mixed results emerged from the studies examining this property, and no clear consensus exists to date among researchers on this question. Of the measures considered, the STAI showed poor construct validity, probably because it seems to measure more depression than anxiety, or more precisely a general factor of negative affect. ${ }^{128,154}$ Therefore, caution should be exercised when using it in older adults with depressive symptoms. On the other hand, the GAS and the GAI performed well on most studies, demonstrating highest correlations with measures of anxiety severity, good discriminant validity, and good balance between specificity and sensitivity in clinical use. . $^{17,26,54,55,69-75,92}$ Additionally, 
containing three conceptually based subscales tapping into various aspects of anxiety symptoms (somatic, cognitive, and affective), the GAS presents one strength over other measures of anxiety designed for older adults, as the researcher and clinician can determine which types of symptoms are more problematic for the subject. For example, if a subject scores very highly on the somatic subscale, this raises attention to the possibility of comorbid physical conditions inflating scores on the subscale. ${ }^{57}$

Further consideration is warranted concerning the insufficiency of appropriate age-relevant norms or clinically useful cutoff scores for most analyzed instruments to date. Findings from many studies did not clearly implicate one cutoff score over another on measures used to identify older adults who may have a diagnosable anxiety disorder. ${ }^{17,20,55}$ This aspect greatly limits their usefulness with older adults, and could lead to the risk of an invalid assessment and diagnosis of anxiety symptoms, with the elevated risk of a subsequent increase in false negatives. ${ }^{176-178}$ Future studies should use updated diagnostic criteria for anxiety disorders, eg, the DSM5, ${ }^{58}$ to determine appropriate cutoff scores for clinically significant anxiety with large clinical samples. ${ }^{21,179}$ Furthermore, there is some evidence that suggests that even low levels of anxiety may disrupt daily living for some older adults enough to warrant clinical intervention. ${ }^{10,16}$ Given the prevalence rates of subclinical anxiety symptoms $(15 \%-52.3 \%$ in community samples and $15 \%-56 \%$ in clinical samples), ${ }^{6}$ cutoff scores for subclinical anxiety could be very helpful in both clinical practice and the research setting. Recent research has used the GAI and the GAS as instruments providing cutoff scores for clinical use with older adults, showing promise for use in varied clinical and research settings. ${ }^{86}$

\section{Future perspectives}

In conclusion, self-report measures for assessing anxiety in older adults could be enhanced through consideration of specific aspects of anxiety assessment associated with aging, such as the foregoing age-related factors. Research should be directed to the development and validation of anxiety instruments specifically designed for geriatric populations or with adequate norms for elderly, with a limited number of items, possibly no reverse-scoring, which could be affected by lower cognitive performance (memory functioning, reading ability, or processing speed) and disability of the older adults, consisting of items that do not rely heavily on somatic symptoms, which could be affected by the presence of more medical illnesses, including poor sleep, and providing appropriate age-relevant norms and clinical cutoff scores for identifying anxiety symptoms, possibly even subthreshold ones.

Only by meeting the specific needs of this population will it be possible to improve the evaluation of anxiety symptoms and provide useful assessment tools to measure symptom severity, monitor change over time in later life, and determine the effects of interventions on late-life anxiety. Importantly, it should be underlined that in any case, the clinical meaning of scores from anxiety measures in the elderly should be integrated with other clues within a multimethod clinical assessment, ${ }^{10,180-183}$ ensuring comprehensive evaluation and avoiding, to whatever extent possible, typical problems associated with a single-method assessment.

\section{Disclosure}

The authors report no conflicts of interest in this work.

\section{References}

1. El-Gabalawy R, Mackenzie C, Thibodeau M, Asmundson G, Sareen J. Health anxiety disorders in older adults: conceptualizing complex conditions in late life. Clin Psychol Rev. 2013;33(8):1096-1105.

2. Cully JA, Stanley MA. Assessment and treatment of anxiety in later life. In: Laidlaw K, Knight B, editors. Handbook of Emotional Disorders in Later Life: Assessment and Treatment. Oxford: Oxford University Press; 2008:233-256.

3. Kessler RC, Angermeyer M, Anthony JC, et al. Lifetime prevalence and age-of-onset distributions of mental disorders in the World Health Organization's World Mental Health Survey Initiative. World Psychiatry. 2007;6(3):168-176.

4. Baxter A, Scott K, Vos T, Whiteford H. Global prevalence of anxiety disorders: a systematic review and meta-regression. Psychol Med. 2013; 43(5):897-910.

5. Wolitzky-Taylor KB, Castriotta N, Lenze EJ, Stanley MA, Craske MG. Anxiety disorders in older adults: a comprehensive review. Depress Anxiety. 2010;27(2):190-211.

6. Bryant C, Jackson H, Ames D. Depression and anxiety in medically unwell older adults: prevalence and short-term course. Int Psychogeriatr. 2009;21(4):754-763.

7. Norton J, Ancelin ML, Stewart R, Berr C, Ritchie K, Carrière I. Anxiety symptoms and disorder predict activity limitations in the elderly. $J$ Affect Disord. 2012;141(2):276-285.

8. Ayers CR, Sorrell JT, Thorp SR, Wetherell JL. Evidence-based psychological treatments for late-life anxiety. Psychol Aging. 2007;22(1): 8-17.

9. Magni G, De Leo D. Anxiety and depression in geriatric and adult medical inpatients: a comparison. Psychol Rep. 1984;55(2): 607-612.

10. Kogan JN, Edelstein BA, McKee DR. Assessment of anxiety in older adults: current status. $J$ Anxiety Disord. 2000;14(2):109-132.

11. Cully JA, Graham DP, Stanley MA, et al. Quality of life in patients with chronic obstructive pulmonary disease and comorbid anxiety or depression. Psychosomatics. 2006;47(4):312-319.

12. Seignourel PJ, Kunik ME, Snow L, Wilson N, Stanley M. Anxiety in dementia: a critical review. Clin Psychol Rev. 2008;28(7): 1071-1082.

13. Therrien Z, Hunsley J. Assessment of anxiety in older adults: a systematic review of commonly used measures. Aging Ment Health. 2012; 16(1):1-16.

14. Lawton MP, Kleban MH, Dean J. Affect and age: cross-sectional comparisons of structure and prevalence. Psychol Aging. 1993;8(2):165. 
15. Person D, Borkovec T. Anxiety disorders among the elderly: patterns and issues. Poster presented at: 103rd Annual Convention of the American Psychological Association; August 11-15, 1995; New York, NY.

16. Kogan J, Edelstein B. Fears in middle-aged and older adults: relations to daily functioning and satisfaction with life. Poster presented at: $31 \mathrm{st}$ Annual Convention of the Association for Advancement of Behavior Therapy; November 15, 1997; Miami, FL.

17. Pachana NA, Byrne GJ, Siddle H, Koloski N, Harley E, Arnold E. Development and validation of the Geriatric Anxiety Inventory. Int Psychogeriatr. 2007;19(1):103-114.

18. Lasoski MC. Reasons for low utilization of mental health services by the elderly. Clin Gerontol. 1986;5(1-2):1-18.

19. Oxman TE, Barrett JE, Barrett J, Gerber P. Psychiatric symptoms in the elderly in a primary care practice. Gen Hosp Psychiatry. 1987;9(3): 167-173.

20. Gould CE, Segal DL, Yochim BP, Pachana NA, Byrne GJ, Beaudreau SA. Measuring anxiety in late life: a psychometric examination of the geriatric anxiety inventory and geriatric anxiety scale J Anxiety Disord. 2014;28(8):804-811.

21. Mohlman J, Bryant C, Lenze EJ, et al. Improving recognition of late life anxiety disorders in Diagnostic and Statistical Manual of Mental Disorders: observations and recommendations of the Advisory Committee to the Lifespan Disorders Work Group. Int J Geriatr Psychiatry. 2012;27(6):549-556.

22. Karlsson B, Klenfeldt IF, Sigström R, et al. Prevalence of social phobia in non-demented elderly from a Swedish population study. Am J Geriatr Psychiatry. 2009;17(2):127-135.

23. World Health Organization. World Report on Ageing and Health. Geneva: WHO; 2015.

24. Hersen M, van Hasselt CB, Goreczny AJ. Behavioral assessment of anxiety in older adults: some comments. Behav Modif. 1993; 17(2):99-112.

25. Naughton C, Feely J, Bennett K. A clustered randomized trial of the effects of feedback using academic detailing compared to postal bulletin on prescribing of preventative cardiovascular therapy. Fam Pract. 2007;24(5):475-480

26. Gottschling J, Segal DL, Häusele C, Spinath FM, Stoll G. Assessment of anxiety in older adults: translation and psychometric evaluation of the German version of the Geriatric Anxiety Scale (GAS). J Psychopathol Behav Assess. 2016;38(1):136-148.

27. Foley D, Ancoli-Israel S, Britz P, Walsh J. Sleep disturbances and chronic disease in older adults: results of the 2003 National Sleep Foundation Sleep in America survey. J Psychosom Res. 2004;56(5):497-502.

28. Mineka S, Watson D, Clark LA. Comorbidity of anxiety and unipolar mood disorders. Annu Rev Psychol. 1998;49:377-412.

29. Beekman AT, de Beurs E, van Balkom AJ, Deeg DJ, van Dyck R, van Tilburg W. Anxiety and depression in later life: co-occurrence and communality of risk factors. Am J Psychiatry. 2000;157(1):89-95.

30. Meeks S, Woodruff-Borden J, Depp CA. Structural differentiation of self-reported depression and anxiety in late life. J Anxiety Disord. 2003;17(6):627-646.

31. Yochim BP, Mueller AE, June A, Segal DL. Psychometric properties of the geriatric anxiety scale: comparison to the Beck Anxiety Inventory and Geriatric Anxiety Inventory. Clin Gerontol. 2010;34(1):21-33.

32. Stanley MA, Novy DM, Bourland SL, Beck JG, Averill PM. Assessing older adults with generalized anxiety: a replication and extension. Behav Res Ther. 2001;39(2):221-235.

33. McLean PD, Woody SR. Anxiety Disorders in Adults: An EvidenceBased Approach to Psychological Treatment. Oxford: Oxford University Press; 2001.

34. Fisher JE, Noll JP. Anxiety disorders. In: The Practical Handbook of Clinical Gerontology. Thousand Oaks (CA): Sage; 1996:304-323.

35. Yesavage JA, Taylor B. Anxiety and dementia. In: Salzman C, Lebowitz BD, editors. Anxiety in the Elderly: Treatment and Research. Heidelberg: Springer; 1991:79-85.

36. Badrakalimuthu VR, Tarbuck AF. Anxiety: a hidden element in dementia. Adv Psychiatr Treat. 2012;18(2):119-128.
37. Salzman C, Lebowitz BD. Anxiety in the Elderly: Treatment and Research. Heidelberg: Springer; 1991.

38. Lenze EJ, Rollman BL, Shear MK, et al. Escitalopram for older adults with generalized anxiety disorder: a randomized controlled trial. JAMA. 2009;301(3):295-303.

39. Gould KR, Ponsford JL, Spitz G. Association between cognitive impairments and anxiety disorders following traumatic brain injury. J Clin Exp Neuropsychol. 2014;36(1):1-14.

40. Gum AM, King-Kallimanis B, Kohn R. Prevalence of mood, anxiety, and substance-abuse disorders for older Americans in the national comorbidity survey-replication. Am J Geriatr Psychiatry. 2009;17(9): 769-781.

41. Porensky EK, Dew MA, Karp JF, et al. The burden of late-life generalized anxiety disorder: effects on disability, health-related quality of life, and healthcare utilization. Am J Geriatr Psychiatry. 2009;17(6):473-482.

42. Wetherell JL, Liu L, Patterson TL, et al. Acceptance and commitment therapy for generalized anxiety disorder in older adults: a preliminary report. Behav Ther. 2011;42(1):127-134.

43. Alwahhabi F. Anxiety symptoms and generalized anxiety disorder in the elderly: a review. Harv Rev Psychiatry. 2003;11(4):180-193.

44. Dennis R, Boddington S, Funnell N. Self-report measures of anxiety: are they suitable for older adults? Aging Ment Health. 2007;11(6): 668-677.

45. Edelstein BA, Woodhead EL, Segal DL, et al. Older adult psychological assessment: current instrument status and related considerations. Clin Gerontol. 2007;31(3):1-35.

46. Hopko DR, Reas DL, Beck JG, et al. Assessing worry in older adults: confirmatory factor analysis of the Penn State Worry Questionnaire and psychometric properties of an abbreviated model. Psychol Assess 2003;15(2):173-183.

47. Crittendon J, Hopko DR. Assessing worry in older and younger adults: psychometric properties of an abbreviated Penn State Worry Questionnaire (PSWQ-A). J Anxiety Disord. 2006;20(8):1036-1054.

48. Nuevo R, Mackintosh MA, Gatz M, Montorio I, Wetherell JL. A test of the measurement invariance of a brief version of the Penn State Worry Questionnaire between American and Spanish older adults. Int Psychogeriatr. 2007;19(1):89-104.

49. Wuthrich VM, Johnco C, Knight A. Comparison of the Penn State Worry Questionnaire (PSWQ) and abbreviated version (PSWQ-A) in a clinical and non-clinical population of older adults. J Anxiety Disord. 2014;28(7): 657-663.

50. Byrne GJ, Pachana NA. Development and validation of a short form of the Geriatric Anxiety Inventory: the GAI-SF. Int Psychogeriatr. 2011;23(1):125-131.

51. Reynolds C, Richmond B, Lowe P. The Adult Manifest Anxiety ScaleElderly Version (AMAS-E). Los Angeles: Western Psychological Services; 2003.

52. Segal DL, June A, Payne M, Coolidge FL, Yochim B. Development and initial validation of a self-report assessment tool for anxiety among older adults: the Geriatric Anxiety Scale. J Anxiety Disord. 2010;24(7): 709-714.

53. Andrew D, Dulin P. The relationship between self-reported health and mental health problems among older adults in New Zealand: experiential avoidance as a moderator. Aging Ment Health. 2007;11(5):596-603.

54. Byrne GJ, Pachana NA, Arnold L, Chalk JB, Appadurai K. Performance characteristics of the geriatric anxiety inventory in memory clinic attendees. Alzheimes Dement. 2008;4(4):T441-T442.

55. Diefenbach GJ, Tolin DF, Meunier SA, Gilliam CM. Assessment of anxiety in older home care recipients. Gerontologist. 2009;49(2):141-153.

56. Johnco C, Wuthrich V, Rapee R. The influence of cognitive flexibility on treatment outcome and cognitive restructuring skill acquisition during cognitive behavioural treatment for anxiety and depression in older adults: results of a pilot study. Behav Res Ther. 2014;57:55-64.

57. Mueller AE, Segal DL, Gavett B, et al. Geriatric Anxiety Scale: item response theory analysis, differential item functioning, and creation of a ten-item short form (GAS-10). Int Psychogeriatr. 2015;27(7): 1099-1111. 
58. American Psychiatric Association. Diagnostic and Statistical Manual of Mental Disorders. 5th ed. Seattle, WA, USA: APA; 2013.

59. Reynolds CR, Richmond BO, Lowe PA. Adult Manifest Anxiety Scale. Los Angeles: Western Psychological Services; 2003.

60. Lowe PA, Reynolds CR. Examination of the psychometric properties of the Adult Manifest Anxiety Scale - elderly version scores. Educ Psychol Meas. 2006;66(1):93-115.

61. Roberts MH, Fletcher RB, Merrick PL. Evaluation of the factor structure of the Adult Manifest Anxiety Scale - elderly version (AMAS-E) in community dwelling older adult New Zealanders. NZ J Psychol. 2016; 45(3):41-47.

62. Lowe PA, Reynolds CR. Exploratory analyses of the latent structure of anxiety among older adults. Educ Psychol Meas. 2000; 60(1):100-116.

63. Cattell RB, Scheier IH. The Meaning and Measurement of Neuroticism and Anxiety. Oxford: Ronald Press; 1961.

64. Endler NS, Edwards JM, Vitelli R. Endler Multidimensional Anxiety Scales (EMAS). Los Angeles: Western Psychological Services; 1991.

65. Finch A, Kendall PC, Montgomery L. Multidimensionality of anxiety in children. J Abnorm Child Psychol. 1974;2(4):331-336.

66. Spielberger CD. Conceptual and methodological issues in anxiety research. In: Anxiety: Current Trends in Theory and Research. Cambridge (MA): Academic Press; 1972:481-493.

67. Reynolds CR. Multitrait validation of the revised Children's Manifest Anxiety Scale for children of high intelligence. Psychol Rep. 1985; 56(2):402.

68. Yesavage JA, Brink TL, Rose TL, et al. Development and validation of a geriatric depression screening scale: a preliminary report. J Psychiatr Res. 1982;17(1):37-49.

69. Byrne GJ, Pachana NA, Goncalves DC, Arnold E, King R, Khoo SK. Psychometric properties and health correlates of the Geriatric Anxiety Inventory in Australian community-residing older women. Aging Ment Health. 2010;14(3):247-254.

70. Ribeiro O, Paúl C, Simões MR, Firmino H. Portuguese version of the Geriatric Anxiety Inventory: transcultural adaptation and psychometric validation. Aging Ment Health. 2011;15(6):742-748.

71. Márquez-González M, Losada A, Fernández-Fernández V, Pachana NA. Psychometric properties of the Spanish version of the Geriatric Anxiety Inventory. Int Psychogeriatr. 2012;24(1):137-144.

72. Massena PN, de Araújo NB, Pachana N, Laks J, de Pádua AC. Validation of the Brazilian Portuguese version of Geriatric Anxiety Inventory: GAI-BR. Int Psychogeriatr. 2015;27(7):1113-1119.

73. Champagne A, Landreville P, Gosselin P, Carmichael PH. Psychometric properties of the French Canadian version of the Geriatric Anxiety Inventory. Aging Ment Health. 2016;2016:1226767.

74. Guan M. Factor structure of the Chinese version of the Geriatric Anxiety Inventory. Ann Gen Psychiatry. 2016;15(1):4.

75. Ferrari S, Signorelli M, Cerrato F, et al. Never too late to be anxious: validation of the Geriatric Anxiety Inventory, Italian version. Clin Ter. 2017;168(2):e120-e127.

76. Johnco C, Knight A, Tadic D, Wuthrich VM. Psychometric properties of the Geriatric Anxiety Inventory (GAI) and its short-form (GAI-SF) in a clinical and non-clinical sample of older adults. Int Psychogeriatr. 2015;27(7):1089-1097.

77. Balsamo M. Personality and depression: evidence of a possible mediating role for anger trait in the relationship between cooperativeness and depression. Compr Psychiatry. 2013;54(1):46-52.

78. Balsamo M, Carlucci L, Sergi MR, Murdock KK, Saggino A. The mediating role of early maladaptive schemas in the relation between co-rumination and depression in young adults. PLoS One. 2015; 10(10): $\mathrm{e} 0140177$.

79. Teachman BA, Siedlecki KL, Magee JC. Aging and symptoms of anxiety and depression: structural invariance of the tripartite model. Psychol Aging. 2007;22(1):160.

80. Balsamo M. Anger and depression: evidence of a possible mediating role for rumination. Psychol Rep. 2010;106(1):3-12.
81. Balsamo M, Imperatori C, Sergi MR, et al. Cognitive vulnerabilities and depression in young adults: an ROC curves analysis. Depress Res Treat. 2013;2013:407602.

82. Carlucci L, Tommasi M, Balsamo M, Furnham A, Saggino A. Religious fundamentalism and psychological well-being: an Italian study. J Psychol Theol. 2015;43(1):23-33.

83. Innamorati M, Tamburello S, Contardi A, et al. Psychometric properties of the attitudes toward self-revised in Italian young adults. Depress Res Treat. 2013;2013:209216.

84. Diefenbach GJ, Bragdon LB, Blank K. Geriatric anxiety inventory: factor structure and associations with cognitive status. Am J Geriatr Psychiatry. 2014;22(12):1418-1426.

85. Gerolimatos LA, Gregg JJ, Edelstein BA. Assessment of anxiety in long-term care: examination of the Geriatric Anxiety Inventory (GAI) and its short form. Int Psychogeriatr. 2013;25(9):1533-1542.

86. Kneebone I, Fife-Schaw C, Lincoln N, Harder H. The Geriatric Anxiety Inventory (GAI): a good option to screen for anxiety in older people after stroke? Int J Stroke. 2015;10(5 Suppl):19.

87. Bendixen AB, Hartberg CB, Selbæk G, Engedal K. Symptoms of anxiety in older adults with depression, dementia, or psychosis: a principal component analysis of the Geriatric Anxiety Inventory. Dement Geriatr Cogn Disord. 2016;42(5-6):310-322.

88. American Psychiatric Association. Diagnostic and Statistical Manual of Mental Disorders. 4th ed. Seattle, WA, USA: APA; 2000.

89. Bolghan-Abadi M, Segal DL, Coolidge FL, Gottschling J. Persian version of the Geriatric Anxiety Scale: translation and preliminary psychometric properties among Iranian older adults. Aging Ment Health. 2013;17(7):896-900.

90. Lin XL, Lu DL, Gottschling J, Segal DL, Tang SY. Validation of a Chinese version of the Geriatric Anxiety Scale among communitydwelling older adults in mainland China. J Cross Cult Gerontol. 2017; 32(1):57-70

91. Hallit S, Hallit R, Hachem D, Nasra MC, Kheir N, Salameh P. Validation of the Arabic version of the Geriatric Anxiety Scale among Lebanese population of older adults. J Psychopathol. 2017;1(1):26-34.

92. Gatti A, Gottschling J, Brugnera A, et al. An investigation of the psychometric properties of the Geriatric Anxiety Scale (GAS) in an Italian sample of community-dwelling older adults. Aging Ment Health. 2017;2017:1347141

93. Derogatis LR. BSI - Brief Symptom Inventory: Administration, Scoring, and Procedures Manual. Minneapolis, MN, USA: National Computer Systems; 1993.

94. Franke G. BSI: Brief Symptom Inventory - Deutsche Version. Göttingen: Beltz; 2000.

95. Wisocki PA, Handen B, Morse CK. The Worry Scale as a measure of anxiety among homebound and community active elderly. Behav Ther (N YN Y). 1986;9(5):91-95.

96. Wisocki PA. The experience of worry among the elderly. In: Davey GC, Tallis F, editors. Worrying: Perspectives on Theory, Assessment and Treatment. Oxford: Wiley; 1994:247-261.

97. Wisocki P, Hunt J, Souza S. The experience of the worry process by elderly chronic worriers. Poster presented at: Second World Congress of Cognitive and Behavior Therapies; 1998; Acapulco, Mexico.

98. Stanley MA, Beck JG, Zebb BJ. Psychometric properties of four anxiety measures in older adults. Behav Res Ther. 1996;34(10):827-838.

99. Hunt S, Wisocki P, Yanko J. Worry and use of coping strategies among older and younger adults. J Anxiety Disord. 2003;17(5):547-560.

100. Hunt SL, Wisocki PA, Roger PR. "What, me worry?" An examination of the literature on worry and the older adult. Behav Ther (N YN Y). 2009;32(1):9-16.

101. Watari KF, Brodbeck C. Culture, health, and financial appraisals: comparison of worry in older Japanese Americans and European Americans. J Clin Geropsychol. 2000;6(1):25-39.

102. Hazlett-Stevens H. Psychological Approaches to Generalized Anxiety Disorder: A Clinician's Guide to Assessment and Treatment. Heidelberg: Springer; 2008. 
103. Fuentes K, Cox B. Assessment of anxiety in older adults: a communitybased survey and comparison with younger adults. Behav Res Ther. 2000;38(3):297-309.

104. Stanley MA, Beck JG, Glassco JD. Treatment of generalized anxiety in older adults: a preliminary comparison of cognitive-behavioral and supportive approaches. Behav Ther. 1996;27(4):565-581.

105. Stanley MA, Beck JG, Novy DM, et al. Cognitive-behavioral treatment of late-life generalized anxiety disorder. J Consult Clin Psychol. 2003;71(2):309-318.

106. Litwin H, Meir A. Financial worry among older people: who worries and why? J Aging Stud. 2013;27(2):113-120.

107. Hervé C, Dufour N, Lebrun C. Adaptation en Français et validation d'une échelle de mesure des peurs des personnes âgées (PPA). Can J Behav Sci. 2014;46(3):313-319.

108. Dewey A. The role of psychological treatments for depression and anxiety in dementia. Int J Older People Nurs. 2016;11(2): $160-162$.

109. Grös DF, Antony MM, Simms LJ, McCabe RE. Psychometric properties of the State-Trait Inventory for Cognitive and Somatic Anxiety (STICSA): comparison to the State-Trait Anxiety Inventory (STAI). Psychol Assess. 2007;19(4):369-381.

110. Spielberger CD. Manual for the State-Trait Anxiety Inventory STAI (Form Y)("Self-Evaluation Questionnaire"). Mountain View (CA): Consulting Psychologists Press; 1983.

111. Knight RG, Waal-Manning HJ, Spears GF. Some norms and reliability data for the State-Trait Anxiety Inventory and the Zung Self-Rating Depression scale. Br J Clin Psychol. 1983;22(4):245-249.

112. Forsberg $\mathrm{C}, \mathrm{Björvell} \mathrm{H}$. Swedish population norms for the GHRI, HI and STAI-state. Qual Life Res. 1993;2(5):349-356.

113. Addolorato G, Ancona C, Capristo E, et al. State and trait anxiety in women affected by allergic and vasomotor rhinitis. J Psychosom Res. 1999;46(3):283-289.

114. Kvaal K, Ulstein I, Nordhus IH, Engedal K. The Spielberger statetrait anxiety inventory (STAI): the state scale in detecting mental disorders in geriatric patients. Int J Geriatr Psychiatry. 2005;20(7): 629-634.

115. Kaneda Y, Fujii A. The relation between anxiety and depressive symptoms in normal subjects and patients with anxiety and/or mood disorders. J Med Invest. 2000;47(1-2):14-18.

116. Stark D, Kiely M, Smith A, Velikova G, House A, Selby P. Anxiety disorders in cancer patients: their nature, associations, and relation to quality of life. J Clin Oncol. 2002;20(14):3137-3148.

117. Millar K, Jelicic M, Bonke B, Asbury A. Assessment of preoperative anxiety: comparison of measures in patients awaiting surgery for breast cancer. Br J Anaesth. 1995;74(2):180-183.

118. Kindler CH, Harms C, Amsler F, Ihde-Scholl T, Scheidegger D. The visual analog scale allows effective measurement of preoperative anxiety and detection of patients' anesthetic concerns. Anesth Analg. 2000;90(3):706-712.

119. Himmelfarb S, Murrell SA. The prevalence and correlates of anxiety symptoms in older adults. J Psychol. 1984;116(2):159-167.

120. Shapiro AM, Roberts JE, Beck JG. Differentiating symptoms of anxiety and depression in older adults: distinct cognitive and affective profiles? Cognit Ther Res. 1999;23(1):53-74.

121. Beck JG, Novy DM, Diefenbach GJ, Stanley MA, Averill PM, Swann AC. Differentiating anxiety and depression in older adults with generalized anxiety disorder. Psychol Assess. 2003;15(2):184-192.

122. Kabacoff RI, Segal DL, Hersen M, van Hasselt VB. Psychometric properties and diagnostic utility of the Beck Anxiety Inventory and the State-Trait Anxiety Inventory with older adult psychiatric outpatients. J Anxiety Disord. 1997;11(1):33-47.

123. Julian LJ. Measures of anxiety: State-Trait Anxiety Inventory (STAI), Beck Anxiety Inventory (BAI), and Hospital Anxiety and Depression Scale - anxiety (HADS-A). Arthritis Care Res (Hoboken). 2011;63 Suppl 11:S467-S472.

124. van Dyke MM, Parker JC, Smarr KL, et al. Anxiety in rheumatoid arthritis. Arthritis Rheum. 2004;51(3):408-412.
125. Ward M, Marx A, Barry N. Psychological distress and changes in the activity of systemic lupus erythematosus. Rheumatology. 2002;41(2): 184-188.

126. White KP, Nielson WR, Harth M, Ostbye T, Speechley M. Chronic widespread musculoskeletal pain with or without fibromyalgia: psychological distress in a representative community adult sample. J Rheumatol. 2002;29(3):588-594.

127. McDonald RJ, Spielberger CD. Measuring anxiety in hospitalized geriatric patients. Ser Clin Community Psychol Stress Anxiety. 1983; 2:135-143.

128. Kennedy BL, Schwab JJ, Morris RL, Beldia G. Assessment of state and trait anxiety in subjects with anxiety and depressive disorders. Psychiatr Q. 2001;72(3):263-276.

129. Bieling PJ, Antony MM, Swinson RP. The State-Trait Anxiety Inventory, trait version: structure and content re-examined. Behav Res Ther. 1998;36(7):777-788.

130. Beck AT, Steer R. Beck Anxiety Inventory Manual. San Diego, CA, USA: Harcourt Brace Jovanovich; 1993.

131. Beck AT, Steer RA. Relationship between the Beck Anxiety Inventory and the Hamilton Anxiety Rating Scale with anxious outpatients. J Anxiety Disord. 1991;5(3):213-223.

132. Gillis MM, Haaga DA, Ford GT. Normative values for the Beck Anxiety Inventory, Fear Questionnaire, Penn State Worry Questionnaire, and Social Phobia and Anxiety Inventory. Psychol Assess. 1995;7(4) $450-455$.

133. Owens K, Hadjistavropoulos T, Asmundson G. Addressing the need for appropriate norms when measuring anxiety in seniors. Aging Ment Health. 2000;4(4):309-314.

134. Wetherell JL, Areán PA. Psychometric evaluation of the Beck Anxiety Inventory with older medical patients. Psychol Assess. 1997;9(2): 136-144.

135. Wetherell JL, Gatz M. The Beck Anxiety Inventory in older adults with generalized anxiety disorder. JPsychopathol Behav Assess. 2005; 27(1):17-24.

136. Fydrich T, Dowdall D, Chambless DL. Reliability and validity of the Beck Anxiety Inventory. J Anxiety Disord. 1992;6(1):55-61.

137. Morin CM, Landreville P, Colecchi C, McDonald K, Stone J, Ling W. The Beck Anxiety Inventory: psychometric properties with older adults. J Clin Geropsychol. 1999;5(1):19-29.

138. Beck AT, Steer RA, Carbin MG. Psychometric properties of the Beck Depression Inventory: twenty-five years of evaluation. Clin Psychol Rev. 1988;8(1):77-100.

139. de Beurs E, Wilson KA, Chambless DL, Goldstein AJ, Feske U. Convergent and divergent validity of the Beck Anxiety Inventory for patients with panic disorder and agoraphobia. Depress Anxiety. 1997; 6(4):140-146.

140. Beck AT, Epstein N, Brown G, Steer RA. An inventory for measuring clinical anxiety: psychometric properties. J Consult Clin Psychol. 1988;56(6):893-897.

141. Montorio I, Nuevo R, Márquez M, Izal M, Losada A. Characterization of worry according to severity of anxiety in elderly living in the community. Aging Ment Health. 2003;7(5):334-341.

142. Newman MG, Castonguay LG, Jacobson NC, Moore GA. Adult attachment as a moderator of treatment outcome for generalized anxiety disorder: comparison between cognitive-behavioral therapy (CBT) plus supportive listening and CBT plus interpersonal and emotional processing therapy. J Consult Clin Psychol. 2015;83(5): 915-925.

143. Meyer TJ, Miller ML, Metzger RL, Borkovec TD. Development and validation of the Penn State Worry Questionnaire. Behav Res Ther. 1990;28(6):487-495.

144. Knight RG, McMahon J, Skeaff CM, Green TJ. Normative data for persons over 65 on the Penn State Worry Questionnaire. NZJ Psychol. 2008;37(1):4-9.

145. Beck JG, Stanley MA, Zebb BJ. Psychometric properties of the Penn State Worry Questionnaire in older adults. J Clin Geropsychol. 1995;1(1):33-42. 
146. Wetherell JL, Gatz M, Craske MG. Treatment of generalized anxiety disorder in older adults. J Consult Clin Psychol. 2003;71(1):31-40.

147. Hundt NE, Armento ME, Porter B, Cully JA, Kunik ME, Stanley M. Predictors of treatment satisfaction among older adults with anxiety in a primary care psychology program. Eval Program Plann. 2013; 37:58-63.

148. Senior AC, Kunik ME, Rhoades HM, Novy DM, Wilson NL, Stanley MA. Utility of telephone assessments in an older adult population. Psychol Aging. 2007;22(2):392.

149. Hopko DR, Bourland SL, Stanley MA, et al. Generalized anxiety disorder in older adults: examining the relation between clinician severity ratings and patient self-report measures. Depress Anxiety. 2000; 12(4):217-225.

150. Mohlman J, Gorman JM. The role of executive functioning in CBT: a pilot study with anxious older adults. Behav Res Ther. 2005; 43(4):447-465.

151. Balsamo M, Innamorati M, van Dam NT, Carlucci L, Saggino A. Measuring anxiety in the elderly: psychometric properties of the State Trait Inventory of Cognitive and Somatic Anxiety (STICSA) in an elderly Italian sample. Int Psychogeriatr. 2015;27(6):999-1008.

152. Balsamo M, Carlucci L, Sergi MR, et al. A new measure for trait and state anxiety: the State Trait Inventory of Cognitive and Somatic Anxiety (STICSA) - standardization in an Italian population. Psicoter Cogn Comport. 2016;22(2):229-232.

153. Ree MJ, French D, MacLeod C, Locke V. Distinguishing cognitive and somatic dimensions of state and trait anxiety: development and validation of the State-Trait Inventory for Cognitive and Somatic Anxiety (STICSA). Behav Cogn Psychother. 2008;36(3):313-332.

154. Balsamo M, Romanelli R, Innamorati M, Ciccarese G, Carlucci L, Saggino A. The State-Trait Anxiety Inventory: shadows and lights on its construct validity. J Psychopathol Behav Assess. 2013;35(4): 475-486.

155. Roberts KE, Hart TA, Eastwood JD. Factor structure and validity of the State-Trait Inventory for Cognitive and Somatic Anxiety. Psychol Assess. 2016;28(2):134-146.

156. Balsamo M, Saggino A. Determining a diagnostic cut-off on the Teate Depression Inventory. Neuropsychiat Dis Treat. 2014;10:987-995.

157. Balsamo M, Giampaglia G, Saggino A. Building a new Rasch-based self-report inventory of depression. Neuropsychiatr Dis Treat. 2014;10: 153-165.

158. Saggino A, Carlucci L, Sergi MR, et al. A validation study of the psychometric properties of the Other as Shamer Scale - 2. SAGE Open. 2017;7(2):2158244017704241.

159. Balsamo M, Macchia A, Carlucci L, et al. Measurement of external shame: an inside view. J Pers Assess. 2015;97(1):81-89.

160. Regier DA, Boyd JH, Burke JD, et al. One-month prevalence of mental disorders in the United States: based on five epidemiologic catchment area sites. Arch Gen Psychiatry. 1988;45(11):977-986.

161. Cohen LL, La Greca AM, Blount RL, Kazak AE, Holmbeck GN, Lemanek KL. Introduction to special issue: evidence-based assessment in pediatric psychology. J Pediatr Psychol. 2006;33(9):911-915.

162. Cairney J, Corna LM, Veldhuizen S, Herrmann N, Streiner DL. Comorbid depression and anxiety in later life: patterns of association, subjective well-being, and impairment. Am J Geriatr Psychiatry. 2008;16(3):201-208

163. Gonda X, Pompili M, Serafini G, Carvalho AF, Rihmer Z, Dome P. The role of cognitive dysfunction in the symptoms and remission from depression. Ann Gen Psychiatry. 2015;14:27.

164. van Hout HP, Beekman AT, de Beurs E, et al. Anxiety and the risk of death in older men and women. Br J Psychiatry. 2004; 185(5):399-404.

165. Allgulander C, Lavori PW. Excess mortality among 3302 patients with “pure" anxiety neurosis. Arch Gen Psychiatry. 1991;48(7):599-602.
166. Frazer DW. The medical issues in geropsychology training and practice. In: Knight BG, Teri L, Wohlford P, Santos J, editors. Mental Health Services for Older Adults: Implications for Training and Practice in Geropsychology. Seattle, WA, USA: American Psychological Association; 1995:63-71.

167. Gould CE, Beaudreau SA, Huh J. A Veterans Health Administration imperative: recommendations for detecting anxiety in older adults. Fed Pract. 2013;30(8):35-42.

168. van der Linden WJ, Hambleton RK. Handbook of Modern Item Response Theory. Heidelberg: Springer; 2013.

169. Hambleton RK, Swaminathan H. Item Response Theory: Principles and Applications. Heidelberg: Springer; 2013.

170. Reise SP, Waller NG. Item response theory and clinical measurement. Annu Rev Clin Psychol. 2009;5:27-48.

171. Krueger RF, Finger MS. Using item response theory to understand comorbidity among anxiety and unipolar mood disorders. Psychol Assess. 2001;13(1):140-151.

172. Leach LS, Christensen H, Mackinnon AJ, Windsor TD, Butterworth P. Gender differences in depression and anxiety across the adult lifespan: the role of psychosocial mediators. Soc Psychiatry Psychiatr Epidemiol. 2008;43(12):983-998.

173. van Dam NT, Earleywine M, Forsyth JP. Gender bias in the sixteenitem Anxiety Sensitivity Index: an application of polytomous differential item functioning. J Anxiety Disord. 2009;23(2):256-259.

174. Hofmann SG, Asnaani MA, Hinton DE. Cultural aspects in social anxiety and social anxiety disorder. Depress Anxiety. 2010;27(12): 1117-1127.

175. Hoge EA, Tamrakar SM, Christian KM, et al. Cross-cultural differences in somatic presentation in patients with generalized anxiety disorder. J Nerv Ment Dis. 2006;194(12):962-966.

176. Grenier S, Préville M, Boyer R, et al. The impact of DSM-IV symptom and clinical significance criteria on the prevalence estimates of subthreshold and threshold anxiety in the older adult population. Am J Geriatr Psychiatry. 2011;19(4):316-326.

177. Morris TL, Masia CL. Psychometric evaluation of the Social Phobia and Anxiety Inventory for Children: concurrent validity and normative data. J Clin Child Psychol. 1998;27(4):452-458.

178. McCabe RE, Miller JL, Laugesen N, Antony MM, Young L. The relationship between anxiety disorders in adults and recalled childhood teasing. J Anxiety Disord. 2010;24(2):238-243.

179. Bryant C, Mohlman J, Gum A, et al. Anxiety disorders in older adults: looking to DSM5 and beyond... . Am J Geriatr Psychiatry. 2013; 21(9):872-876.

180. Lenze EJ, Wetherell JL. Anxiety disorders: new developments in old age. Am J Geriatr Psychiatry. 2011;19(4):301-304.

181. Hunsley J. Introduction to the special section on incremental validity and utility in clinical assessment. Psychol Assess. 2003;15(4): $443-445$.

182. Edelstein BA, Martin RR, Gerolimatos LA. Assessment in geriatric settings. In: Weiner IB, Graham JR, Naglieri JA, editors. Handbook of Psychology: Volume 10 - Assessment Psychology. 2nd ed. Hoboken (NJ): Wiley; 2003:425-448.

183. Carmin C, Ownby RL. Assessment of anxiety in older adults. In: Lichtenberg PA, editor. Handbook of Assessment in Clinical Gerontology. 2nd ed. Cambridge (MA): Academic Press; 2010:45-60.

184. Spielberger CD. Inventario per l'Ansia di «Stato» e di «Tratto»: Nuova Versione Italiana dello STAI Forma Y - Manuale. Florence: Giunti Organizzazioni Speciali; 1989.

185. Beck AT, Epstein N, Brown G, Steer RA. An inventory for measuring clinical anxiety: psychometric properties. J Consult Clin Psychol. 1988;56(6):893.

186. Hewitt PL, Norton GR. The Beck Anxiety Inventory: a psychometric analysis. Psychol Assess. 1993;5(4):408-412. 
Clinical Interventions in Aging

\section{Publish your work in this journal}

Clinical Interventions in Aging is an international, peer-reviewed journal focusing on evidence-based reports on the value or lack thereof of treatments intended to prevent or delay the onset of maladaptive correlates of aging in human beings. This journal is indexed on PubMed Central, MedLine,

CAS, Scopus and the Elsevier Bibliographic databases. The manuscript management system is completely online and includes a very quick and fair peer-review system, which is all easy to use. Visit http://www.dovepress. $\mathrm{com} /$ testimonials.php to read real quotes from published authors.

Submit your manuscript here: http://www.dovepress.com/clinical-interventions-in-aging-journal 